\title{
NMDA and Non-NMDA Glutamate Receptors in Auditory Transmission in the Barn Owl Inferior Colliculus
}

\author{
Daniel E. Feldman and Eric I. Knudsen \\ Department of Neurobiology, Stanford University School of Medicine, Stanford, California 94305-5401
}

The pharmacology of auditory responses in the inferior colliculus (IC) of the barn owl was investigated by iontophoresis of excitatory amino acid receptor antagonists into two different functional subdivisions of the IC, the external nucleus (ICX) and the lateral shell of the central nucleus (lateral shell), both of which carry out important computations in the processing of auditory spatial information. Combined application of the NMDA receptor antagonist 2-amino-5-phosphonovaleric acid (AP5) and the non-NMDA receptor antagonist 6-cyano-5-nitroquinoxaline-2,3-dione (CNQX) significantly reduced auditory-evoked spikes at all sites in these two subdivisions, and completely eliminated responses at many locations. This suggests that excitatory amino acid receptors mediate the bulk, if not all, of auditory responses in the ICX and lateral shell.

NMDA and non-NMDA receptors contributed differently to auditory responses in the two subdivisions. In the ICx, AP5 significantly reduced the number of auditory-evoked spikes at every site tested. On average, AP5 eliminated $55 \%$ of auditory-evoked spikes at multiunit sites and $64 \%$ at singleunit sites in this structure. In contrast, in the lateral shell, AP5 significantly reduced responses at less than half the sites tested, and, on average, AP5 eliminated only $19 \%$ of spikes at multiunit sites and $25 \%$ at single-unit sites. When the magnitude of response blockade produced by AP5 at individual multiunit sites was normalized to adjust for siteto-site differences in the efficacy of iontophoresed AP5 and CNQX, AP5 blockade was still significantly greater in the ICX than the lateral shell. CNQX application strongly reduced responses in both subdivisions. These data suggest that NMDA receptor currents make a major contribution to auditory responses in the $\mathrm{ICX}$, while they make only a small contribution to auditory responses in the lateral shell. NonNMDA receptor currents, on the other hand, contribute to auditory responses in both subdivisions, and mediate the bulk of auditory transmission in the lateral shell.

The time course of the NMDA receptor contribution to ICx auditory responses and the dependence of this contribution on stimulus level were both examined in detail. AP5 preferentially blocked spikes late in ICx auditory responses, while

\footnotetext{
Received Dec. 27, 1993; revised Mar. 24, 1994; accepted Mar. 29, 1994.

We thank Michael Brainard, Yale Cohen, and Richard Mooney for reviewing the manuscript. This work was supported by NIH R01 DC00155-14, and a Howard Hughes Medical Institute Predoctoral Fellowship to D.E.F.

Correspondence should be addressed to Daniel Feldman, Department of Neurobiology, Fairchild Building, Stanford University School of Medicine, Stanford, CA 94305-5401.

Copyright (C) 1994 Society for Neuroscience $0270-6474 / 94 / 145939-20 \$ 05.00 / 0$
}

CNQX blocked spikes equally throughout the responses. This pattern is consistent with a simple model in which slow NMDA receptor currents and faster non-NMDA receptor currents are both activated by auditory inputs to ICX neurons. When stimuli of varying sound intensity were used to evoke responses across the dynamic range of ICx neurons, AP5 blocked the same proportion of spikes at all response levels, indicating that NMDA receptor currents do not display a threshold for activation over the dynamic range of ICx neurons.

In all these respects, the pharmacology of auditory responses in the ICX appears similar to that of visual responses in the kitten's visual cortex (Fox et al., 1989, 1990), one of several systems in which NMDA receptors have been hypothesized to play a role in both information processing (Daw et al., 1993) and developmental plasticity (e.g., Bear et al., 1990). In the owl's ICx, NMDA receptors may have a similar dual role, contributing to the specialized information processing that underlies the synthesis of the auditory map of space, as well as to the experience-dependent synaptic modifications that shape the map during development.

IKey words: inferior colliculus, excitatory amino acid, NMDA receptors, non-NMDA receptors, auditory system, barn owI]

The inferior colliculus (IC) is an important processing center that receives converging inputs from all portions of the auditory system (Irvine, 1986; Oliver and Huerta, 1992), and integrates information from many of these sources to form high-order representations of auditory input. For example, IC circuitry compares information about the relative sound levels at the two ears (Faingold et al., 1989a, 1991; Park and Pollack, 1993), and represents this information systematically as a map of interaural level difference (Wenstrup et al., 1986; Irvine and Gago, 1990; Mogdans and Knudsen, 1993), an important cue for sound localization. The IC homolog in electric fish, the torus semicircularis, integrates information about the amplitude and phase of external electric fields as part of the processing subserving the jamming avoidance response (Heilegenberg, 1991). The function of IC circuitry is particularly well understood in the barn owl (Tyto alba), where distinct steps in the computation of sound source location take place in separate, well defined subdivisions of the IC (Wagner et al., 1987; Konishi et al., 1988). This compartmentalization of function makes it possible to examine the relationship between different types of neuronal computation and the pharmacology of the circuits mediating them.

The subdivisions of the owl's IC (Fig. 1) are distinguished on the basis of anatomical connections, cell morphology, and auditory physiology (Knudsen, 1983; Takahashi and Konishi, 1986; Wagner et al., 1987; Fujita and Konishi, 1991). The large, tono- 
Central Nucleus $\quad$ External Nucleus

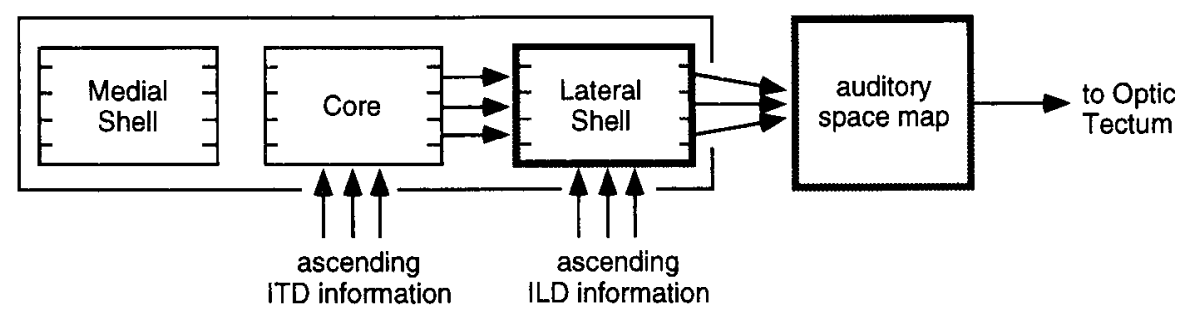

Figure 1. Subdivisions of the barn owl's inferior colliculus. The central nucleus of the IC is tonotopically organized (horizontal tick marks) and is divided into core, medial shell, and lateral shell subdivisions. These subdivisions project to the thalamus (not shown), and also along a wellcharacterized pathway leading to the external nucleus and optic tectum (arrows). ITD information arrives at the core of the central nucleus from nuclei lower in the brainstem. The core projects to the lateral shell, where ITD information is merged with incoming ILD information from other brainstem sources. The lateral shell projects to the external nucleus, combining ITD and ILD information across frequency channels (converging arrows) and producing a map of auditory space in the $\mathrm{ICx}$. This auditory space map is conveyed to the optic tectum, where it aligns with the retinotectal map of visual space. In this study we assessed the pharmacology of auditory responses in the lateral shell and ICx (thick boxes).

topically arranged central nucleus is composed of medial shell, core, and lateral shell regions. Neurons in these regions are sharply tuned for frequency and in addition are sensitive to interaural time difference (ITD) and/or interaural level difference (ILD), the principle binaural cues used by the barn owl for sound localization. Neurons in the medial shell encode only ILD; neurons in the core encode only ITD. In the lateral shell of the central nucleus (here referred to as the lateral shell), ITD information from the core and ILD information from other brainstem nuclei are combined within narrow frequency channels to produce single neurons that encode both ITD and ILD.

The lateral shell projects to the nontonotopic external nucleus of the IC (ICx). In the ICx, ITD and ILD information are integrated across frequency channels to produce neurons that are broadly tuned for frequency, but sharply tuned for specific values of ITD and ILD, and therefore for sound source location (Takahashi and Konishi, 1986; Brainard et al., 1992). In the same integrative step, these neurons are organized according to the locations of their spatial receptive fields to form an auditory map of space (Knudsen and Konishi, 1978). The auditory space map is relayed topographically to the optic tectum (the avian equivalent of the mammalian superior colliculus), where it is congruent with the visual space map, and where it mediates orienting responses to sound stimuli (Knudsen et al., 1993).

In this report, we compare the pharmacology of auditory transmission in the lateral shell, which integrates information within frequency channels, with that in the $\mathrm{ICx}$, which integrates information across frequency channels and creates a map of space. At the outset of this study, the pharmacology of auditory transmission in the avian IC was unknown. We focused on transmission via excitatory amino acid receptors, since these receptors are thought to subserve most fast excitatory transmission in the CNS (Nicoll et al., 1990). The family of excitatory amino acid receptors is routinely divided into NMDA and nonNMDA receptors (Mayer and Westbrook, 1985; Nicoll et al., 1990) on the basis of several characteristics. NMDA receptors are distinguished biophysically by the time course, ionic composition, and voltage dependence of their currents, and pharmacologically by their susceptibility to a specific set of antagonists, including 2-amino-5-phosphonovaleric acid (AP5). Because of the properties of their currents, NMDA receptors are thought to confer on neurons unique processing capabilities, including gain control (Fox et al., 1990), and in addition have been implicated in many types of synaptic plasticity (for a review, see Shatz, 1990).
It was reasonable to expect that synaptic transmission in the IC should be mediated by excitatory amino acid receptors. Glutamate binding sites exist in chick IC (Mitsacos et al., 1990), but it is not known if these sites represent receptors that mediate auditory responses, nor is it known which subtypes of glutamate receptor they represent. In the mammalian $\mathrm{IC}$, there is strong evidence suggesting that auditory transmission is mediated by an excitatory amino acid. Not only are significant levels of glutamate (Adams and Wenthold, 1979; Golden et al., 1989), glutamate-immunoreactive neurons (Otterson and Storm-Mathisen, 1984), and glutamate binding sites (Greenamyre et al., 1984; Cotman and Iversen, 1987) present, but NMDA and nonNMDA receptor-mediated excitatory potentials have been observed in some IC neurons in vitro (Smith, 1992). In addition, an in vivo iontophoretic study has implicated NMDA receptors in mediating auditory responses in the central nucleus (Faingold et al., 1989b). Here, we use iontophoresis of NMDA and nonNMDA receptor antagonists to demonstrate the relative contributions of these two receptor subtypes to auditory transmission in the ICx and lateral shell. Pharmacological differences between these subdivisions may reflect the different kinds of information processing that occur in these structures.

In addition to any pharmacological specialization related to information processing, synaptic transmission in $\mathrm{ICx}$ may be further specialized to support the experience-dependent plasticity that occurs in this subdivision. The mutual alignment of auditory and visual space maps in the optic tectum is known to be maintained through experience-dependent synaptic modification in the ICx (Brainard and Knudsen, 1993). When owls are reared wearing prismatic spectacles that displace the visual world, auditory receptive fields in the ICX shift by an amount that corresponds to the visual displacement. As a consequence of this shift, the auditory and visual maps of space in the optic tecta regain their mutual alignment. NMDA receptors may bc involved in this adjustment process by analogy to other systems, including the optic tectum of Xenopus, in which an NMDA receptor-dependent mechanism maintains the mutual alignment of visual maps from the two eyes (Scherer and Udin, 1989). NMDA receptors have also been implicated in experience-dependent synaptic modification in a variety of other systems (e.g., Cline et al., 1987; Bear et al., 1990; Schmidt, 1990). We therefore looked for evidence of NMDA receptor-mediated transmission in the $\mathrm{ICx}$, as a first step in assessing what role these receptors may play in the experience-dependent plasticity that occurs in this subdivision. 


\section{Materials and Methods}

Six barn owls, aged $82-455 \mathrm{~d}$, were used in this study. These owls were reared in the barn owl colony in the Stanford University Research Animal Facility. Experimental protocols were approved by the Institutional Animal Care and Use Committee and are in accordance with the guidelines set by the Society for Neuroscience.

Preparation for electrophysiological recording. Several days before the initial experiment, each owl was anesthetized with $2 \%$ halothane in a nitrous oxide/oxygen (4:5) mixture. A stainless steel headpiece was mounted to the skull and a craniotomy was made over the optic tectum and inferior colliculus. Chloramphenicol $(0.5 \%)$ was applied to the dura, wound edges were infiltrated with lidocaine, and the craniotomy was sealed with dental acrylic. The bird was then allowed to recover from anesthesia and was returned to its home cage. At the start of subsequent electrophysiological recording sessions, the owl was anesthetized with the halothane mixture, hydrated with a subdermal injection of $2.5 \%$ dextrose in $0.76 \%$ saline, wrapped in a soft leather jacket, and transferred to a sound-attenuating chamber where recordings were made. The head was aligned using retinal landmarks and the dental acrylic was removed from the craniotomy. Earphones for dichotic stimulation were placed in the external ear canals.

Pilot studies showed that halothane, as well as several other anesthetics tested (ketamine and isoflurane), altered auditory responsiveness in the inferior colliculus, and therefore all recordings in this study were made under unanesthetized conditions. The bird was allowed to recover from the initial dose of anesthesia until auditory responses in the IC returned to normal levels. Unanesthetized birds typically remained in a quiet state for $40-50$ min periods, during which pharmacological measurements were made. When a measurement was completed at one site, or whenever the bird showed signs of discomfort, it was briefly reanesthetized with the halothane mixture. Each experiment consisted of multiple measurements, performed when the bird was quiet, interspersed with short periods of supplemental anesthesia and recovery. At the end of each experiment, chloramphenicol was applied to the brain surface, the craniotomy was sealed with dental acrylic, and the bird was returned to its home cage.

Auditory stimuli. Experiments were carried out in a sound-attenuating chamber (IAC). Auditory stimuli were generated digitally and presented dichotically through matched Knowles earphones (ED-1941) coupled to damping assemblies (BF-1743). The frequency response of the earphones was flat within $\pm 2 \mathrm{~dB}$ over $4-10 \mathrm{kHz}$. Output level was linear within $0.2 \mathrm{~dB}$ over a $45 \mathrm{~dB}$ dynamic range. Noise stimuli were $50 \mathrm{msec}$ in duration, with 0 msec rise and fall times, and high-pass filtered at 4 $\mathrm{kHz}$ to minimize sound propagation through the owl's interaural canal (Moiseff and Konishi, 1981). Tone bursts were also $50 \mathrm{msec}$ in duration and had $5 \mathrm{msec}$ rise and fall times.

To determine ILD tuning, a series of noise stimuli was presented in which the ILD was varied from $30 \mathrm{~dB}$ left ear greater to $30 \mathrm{~dB}$ right ear greater in 2-3 dB increments. Stimuli within a series were presented in randomized order with an interstimulus interval of $0.7-1$ sec. The series was presented 5-10 times. The response of a unit to each stimulus was quantified as the number of spikes that occurred during the 100 msec period following stimulus onset minus the number of spikes occurring in the $100 \mathrm{msec}$ prior to the stimulus (spontaneous rate). The peak of the tuning curve was defined as the midpoint of the range of ILD values evoking at least half-maximal responses, and was termed the "best ILD." The width of the ILD tuning curve was defined as the range of values evoking at least half-maximal responses.

To determine ITD tuning, 5-10 series of noise stimuli varying in ITD from $200 \mu \mathrm{sec}$ right ear leading to $200 \mu \mathrm{sec}$ left ear leading, in 10-20 $\mu$ sec increments, were similarly presented. The width of the ITD tuning curve was defined as the range of ITD values evoking at least halfmaximal responses, and the midpoint of this range was termed the "best ITD." When measuring ITD tuning, ILD was held constant at the best ILD; when measuring ILD tuning, ITD was held constant at the best ITD. In both cases, average binaural level (the sum of the levels at each of the two ears, divided by two) was held constant at $20 \mathrm{~dB}$ above average unit threshold. To determine frequency tuning, 5-10 series of tonal stimuli, varying from 2.0 to $10.0 \mathrm{kHz}$ in $0.5 \mathrm{kHz}$ increments, were presented at best ITD and best ILD. "Best frequency" and width of frequency tuning were defined in the same manner as described above for ILD and ITD tuning.

To determine the level-response function, the average binaural sound level of noise stimuli at the best ITD and best ILD was varied in $2 \mathrm{~dB}$ increments over an 18-23 dB range. Unit threshold was defined as the average binaural level at which stimuli evoked activity three SDs above spontaneous rate. Typically, responses increased with increasing average binaural level above unit threshold until a plateau response was reached, above which greater levels failed to evoke larger responses. The exact range of levels used to construct the level-response curve was selected for each unit to sample the entire dynamic range of the level-response function, from threshold to maximum response.

Iontophoresis electrodes. Iontophoresis electrodes (Armstrong-James and Millar, 1979) were made by inserting a $7 \mu \mathrm{m}$ carbon fiber (Amoco Performance Products, Alpharetta, GA) into the central barrel of an Omega-dot glass five-barrel capillary (World Precision Instruments). After pulling, tips were cut back so that the internal diameter of each outer barrel was 1-3 $\mu \mathrm{m}$, and outer barrels were flush with the carbon fiber; $1 \mathrm{M} \mathrm{NaCl}$ was used to make contact with the carbon fiber for recording. Each of the four outer barrels was filled with a drug or current balance solution, and had impedances of $2-15 \mathrm{M} \Omega$ at $1 \mathrm{kHz}$. Current balance barrels were filled with $100 \mathrm{~mm} \mathrm{NaCl}$ and adjusted to $\mathrm{pH} 7.4$ with $0.10 \mathrm{~m} \mathrm{NaOH}$. Unused barrels were filled with distilled water. Chloride-coated silver wire was used to make electrical contact with solutions in each barrel.

Drug solutions. Solutions were made in $\mathrm{dH}_{2} \mathrm{O}$ at the following concentrations and adjusted with $\mathrm{NaOH}$ to achieve the following $\mathrm{pH}$ values: NMDA, $50 \mathrm{~mm}, \mathrm{pH} 4.5$; quisqualate (QA), $20 \mathrm{~mm}$, pH 7.0; DL-AP5, $67 \mathrm{~mm}, \mathrm{pH} 7.4$; CNQX, $10 \mathrm{~mm}, \mathrm{pH}$ 8.0. Solutions were passed through a $0.2 \mu \mathrm{m}$ filter and refrigerated for up to 2 weeks without a noticeable loss of potency. pH control solutions were made by adding $0.10 \mathrm{M} \mathrm{NaOH}$ to $100 \mathrm{~mm} \mathrm{NaCl}$.

Iontophoresis protocols. DL-AP5 was used in this study as an NMDA receptor antagonist, and CNQX as a non-NMDA receptor antagonist (Nicoll et al., 1990). Drugs were applied by iontophoresis (NeuroData IPX-5) at the recording site. In early experiments, current balance was used, but this was abandoned after $\mathrm{pH}$-matched saline ejections repeatedly produced no effects on auditory responses or spontaneous firing of IC or optic tectal cells (e.g., see Fig. 5). Retaining currents (5 nA) were routinely used on all barrels. Two standard ejection currents $(25$ and $40 \mathrm{nA}$ ) were used for the antagonists AP5 and CNQX. AP5 applied at these current levels antagonized neuronal responses to NMDA without antagonizing responses to QA (see Results), indicating that AP5 applied at these standard levels blocked NMDA but not non-NMDA receptors. The concentration and spatial distribution of AP5 and CNQX produced in the brain by ejection at the standard currents are unknown. Fox et al. (1989) have calculated, however, based on analogy to norepinephrine iontophoresis, that AP5 ejection currents of this magnitude produce a sphere of AP5 whose concentration falls off with distance from the electrode tip, with the minimum dose for blocking NMDA receptors (25 $\mu \mathrm{M}$; Artola and Singer, 1987) occurring some 100-200 $\mu \mathrm{m}$ from the electrode tip.

Multiunit sites, typically consisting of three to five units, were selected for pharmacological measurements if they could be assigned unambiguously to either the ICx or the lateral shell, using the criteria detailed below. Single units, isolated using a slope-amplitude window discriminator, were additionally selected by the biphasic shape of the extracellularly recorded action potential, indicating a somatic and not a fiber spike. Once a sile was selected, ITD, ILD, and frequency tuning were determined. The pharmacology was then assayed by measuring responses to broad-band sound stimuli, presented every 1-2 sec, during a control period and during several subsequent periods of drug application that were separated by recovery periods. Total recording time for each site was $10-20 \mathrm{~min}$. Sound stimuli were $4-10 \mathrm{kHz}$ band-passed noise bursts, with $50 \mathrm{msec}$ duration and $0 \mathrm{msec}$ rise and fall times, and were presented at the unit's best ITD and best ILD, $20 \mathrm{~dB}$ above response threshold.

Drugs were applied using one of three standard protocols. In the standard recovery protocol, control responses were collected for $2 \mathrm{~min}$, during which time retaining currents were applied to all drug barrels. Next, AP5 or CNQX was ejected at one of the standard current levels ( 25 or $40 \mathrm{nA}$ ) for at least $2 \mathrm{~min}$. Iontophoresis continued until responses stabilized at a plateau level. The drug was then halted by reapplication of the retaining current, and the responses were allowed to recover for a period of twice the length of time over which the drug had been applied. If responses did not recover to a criterion of $70 \%$ of the control response level, the data were discarded. The second protocol, the $A / A+C$ protocol, was designed to compare the magnitude of response blockade produced by AP5 application to that produced by combined application of both AP5 and CNQX. After control responses were collected, AP5 was ejected at one of the standard current levels for $2 \mathrm{~min}$, and responses were 
allowed to stabilize at a plateau level. At this point, CNQX was ejected at the same current level along with the AP5 for another 2 min, and responses were again allowed to plateau. Finally, both drugs were retained and the responses were allowed to recover using the same criterion as in the standard recovery protocol. The third protocol was the dose-response protocol, in which the effects of several different ejection currents of antagonist were compared. After the collection of control responses, AP5 or CNQX was ejected at incrementally increasing currents, and the response level was allowed to plateau between each increment in current. Typically, five levels of ejection current ranging from 5 to $80 \mathrm{nA}$ were applied, each for 2-3 min. Because of the long period of drug application (10-15 min), recoveries were slow and therefore not followed. However, standard doses of AP5 and CNQX administered using this protocol reduced auditory responses by amounts that were indistinguishable from those observed using the standard recovery protocol (see Results).

Data collected using the standard recovery protocol and the $\mathrm{A} / \mathrm{A}+\mathrm{C}$ protocol were accepted for analysis only if (1) there was at least a 70\% recovery of responses after drug application and (2) both antagonists effectively blocked responses either to auditory stimuli or to the appropriate agonist, at some point in the same penetration. Sites were accepted for analysis in the dose-response protocol only if the bird remained quiet throughout the entire measurement period.

Analysis. Reduction of auditory responses was quantified as the difference between the mean number of auditory-evoked spikes (above the spontaneous rate) measured during the final 40 stimuli under control conditions, and that measured during the final 40 stimuli of each drug condition (i.e., the plateau response). This difference was expressed as a percentage of control response level and was termed "response blockade." A metric $A / A+C$ was calculated for sites at which the $\mathrm{A} / \mathrm{A}+\mathrm{C}$ protocol was applied. This metric was defined as the magnitude of response blockade (from control levels) produced by AP5, divided by the magnitude of response blockade (from control levels) produced by simultaneous application of AP5 and CNQX. The metric was designed to normalize the amount of response blockade produced by AP5 for the general effectiveness of excitatory amino acid antagonists applied at that site. A value of 1 for this metric means that AP5 blockade completely accounts for the total response blockade produced by simultaneous AP5 and CNQX application at that current level; a value of 0 means that AP5 failed to block auditory responses, but combined AP5 and CNQX did significantly reduce responses. Negative values of the metric mean that AP5 caused a nominal increase rather than a decrease of auditory responses; however, such increases were never significant.

For each site tested with the standard recovery protocol, the statistical significance of response blockade was determined using an unpaired two-tailed $t$ test to compare the magnitude of the final 40 control responses with that of the final 40 responses collected during drug application. For each site tested with the $\mathrm{A} / \mathrm{A}+\mathrm{C}$ protocol, the statistical significance of differences between control, AP5, and simultaneous AP5 + CNQX conditions was determined using a one-way ANOVA, followed by the Tukey procedure, on the final 40 responses of each epoch. The Tukey procedure is a standard post hoc test that determines whether two groups within a larger number of groups in an ANOVA are significantly different from one another. The magnitude of response blockade, and the values of the $\mathrm{A} / \mathrm{A}+\mathrm{C}$ metric were compared between populations of ICx and lateral shell sites using unpaired two-tailed $t$ tests. The criterion for significance throughout this study was $p<0.05$.

Peristimulus time histograms (PSTHs) were constructed from responses collected during control periods and periods of drug application, in order to evaluate the effects of AP5 and CNQX on early and late portions of the auditory response. PSTHs had $1 \mathrm{msec}$ time bins, and were aligned by stimulus onset. A curve representing the effects of drug application on the time course of the response was calculated by dividing, at each $1 \mathrm{msec}$ bin, the value of the PSTH compiled during drug application by that of the PSTH compiled during the control period. Such curves were described by linear regressions, and were compared with other curves by an extension of the general linear test (Neter, 1990). In this test, the sum squared error was calculated for each regression separately (full model), and subsequently for a single regression through both sets of data together (restricted model). An $F$ value was calculated from these sum squared errors, taking into account the degrees of freedom for each model, using the general linear test. An $F$ value that gave $p<0.05$ was interpreted to mean that the data were better fit by two separate regressions than they were by a single regression, and therefore that the slopes of the regression lines were significantly different.
The mean arrival time of spikes during the response was also calculated as an index for comparing the relative blockade of spikes early and late in the response. This index was calculated from the arrival times, measured relative to the response latency, of spikes occurring within $50 \mathrm{msec}$ of the latency, in order to avoid a contribution by off responses. Latency was measured from the PSTH and was defined as the first of two consecutive $1 \mathrm{msec}$ time bins containing a number of spikes that was at least two SDs greater than the mean of the spontaneous rate. The mean spike arrival time was chosen for this index, rather than the median, because the mean is more sensitive to variations at the extremes of the distribution (i.e., elimination of very early or very late spikes). The value of this index increases or decreases from its control value with the preferential blockade of early or late spikes, respectively.

Criteria for assignment of sites to IC subdivisions. Two kinds of criteria were used to assign units to IC subdivisions: (1) location relative to known locations in the optic tectum, as measured by microdrive coordinates; and (2) physiological criteria that distinguish $\mathrm{ICx}$ units from lateral shell units. Lateral shell units were identified by frequency tuning that was narrow (width at half-height $\leq 1.5 \mathrm{kHz}$ ) and best frequencies that progressed from low to high across units in a dorsoventral penetration. In addition, lateral shell units were tuned for ITD and ILD, and best ILD did not progress across sites in a dorsoventral penetration. ICx units were identified on the basis of broad frequency tuning curves (width at half-height $\geq 2.0 \mathrm{kHz}$ ), best frequencies that did not progress dorsoventrally, and best ILDs that progressed from right ear greater to left ear greater dorsoventrally. These criteria have been confirmed by anatomical reconstructions, and reliably differentiate each of these subdivisions from nearby auditory structures (Brainard and Knudsen, 1993). Units that did not meet these criteria, and were presumably located in other subdivisions of the IC, were excluded from this sludy.

\section{Results}

Selectivity of AP5 blockade at standard current levels

Standard ejection current levels for AP5 application in this study were $25 \mathrm{nA}$ and $40 \mathrm{nA}$. The selectivity of receptor antagonism produced by these ejection currents was assessed at 10 multiunit sites in the ICx. Data from one such site are shown in Figure $2 A$. NMDA, an agonist at its own receptor, and quisqualate (QA), an agonist at non-NMDA receptors, were iontophoresed alternately to evoke robust but nonsaturating discharges. After a control period, AP5 was iontophoresed at the $40 \mathrm{nA}$ current level, and the NMDA-evoked responses at this site were wholly suppressed, while the QA-evoked responses remaincd csscntially unaffected. To quantify the effect of AP5, the average peak firing rate was measured for NMDA-evoked and QA-evoked responses during the control period and during AP5 application. AP5 at $25 \mathrm{nA}(n=7)$ reduced NMDA-evoked responses by 91 $\pm 12 \%( \pm \mathrm{SD})$ from control levels, while reducing QA-evoked responses by only $7 \pm 13 \%$ from control levels. Similarly, 40 nA AP5 $(n=6)$ reduced NMDA-evoked responses by $95 \pm 7 \%$ from control levels, while reducing QA-evoked responses by only $9 \pm 9 \%$ from control levels (Fig. $2 B$ ). AP5 was applied at current levels greater than $40 \mathrm{nA}$ at two ICX sites, and at these sites, the specificity of AP5 declined with ejection currents above $60 \mathrm{nA}$. These data indicate that iontophoresis of 25 and $40 \mathrm{nA}$ AP5 produces a selective antagonism of NMDA receptors relative to non-NMDA receptors in the ICx. The selectivity of CNQX was not tested, since blockade by CNQX is likely to reduce NMDA receptor currents indircctly, by virtuc of their voltage sensitivity (e.g., Salt and Eaton, 1989; Armstrong-James et al., 1993).

\section{Dose response of $A P 5$ and $C N Q X$ blockade of auditory responses}

In addition to being selective, the standard AP5 ejection currents reduced auditory responses by an amount near the maximum attainable by iontophoresed AP5. Dose-response curves were 

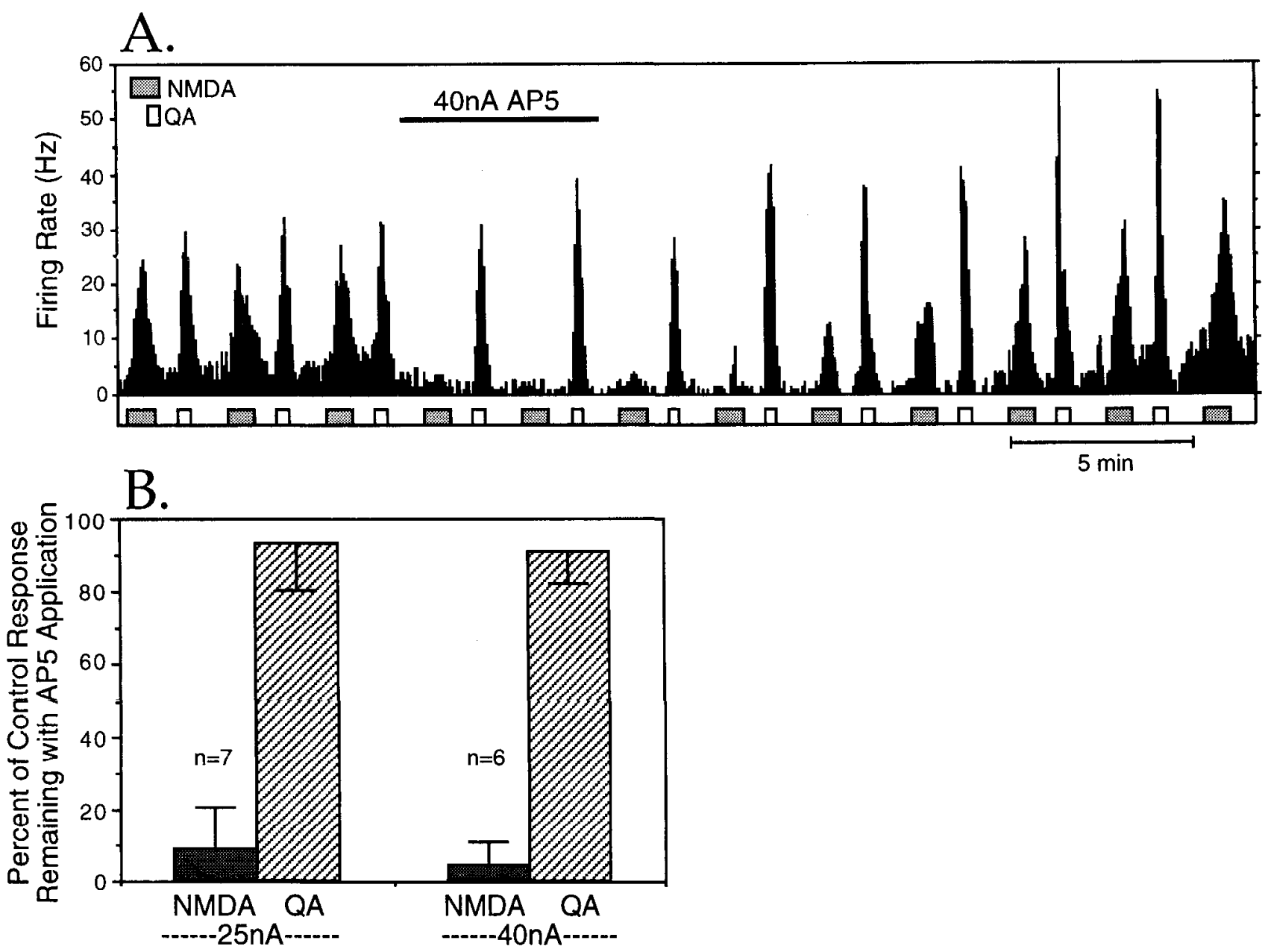

Figure 2. Standard AP5 ejection currents selectively antagonized NMDA receptor-mediated responses. $A$, Multiunit responses to alternately iontophoresed NMDA and quisqualate $(Q A)$ at a representative ICx site. Each bin represents firing rate integrated over a 2 sec period, and the data were smoothed with a two-bin running average. Upward deflections in the lower trace indicate iontophorcsis of either $35 \mathrm{nA}$ NMDA or $34 \mathrm{nA}$ QA Holding currents $(5 \mathrm{nA})$ were applied between ejections. AP5, applied at $40 \mathrm{nA}$ at the time indicated by the line segment, potently and reversibly blocked responses to applied NMDA while sparing responses to applied QA. B. Summary data from 10 ICx sites to which AP5 was applied at either $25 \mathrm{nA}$ or $40 \mathrm{nA}$. For each site, the magnitude of blockade produced by AP5 was quantified as the percentage reduction in peak firing rate elicited by NMDA or QA from respective control levels. On the ordinate, $100 \%$ denotes no block from control levels, and $0 \%$ denotes complete block. Error bars are 1 SD.

measured for AP5's blockade of auditory responses of single ICx units $(n=9)$. Response blockade increased monotonically with increasing ejection currents of AP5 until a plateau level was reached, beyond which increasing AP5 currents, up to 80 nA, had no further effect on auditory responses (Fig. $3 A$ ). The responses of all cells tested plateaued with AP5 ejection currents of $60 \mathrm{nA}$ or less. Though the maximum blockade varied from unit to unit, the shape of the dose-response curve was quitc consistent, and therefore the curves were normalized so that their mean shape could be determined. Normalization involved (1) finding the lowest AP5 ejection current above which increasing currents failed to increase response blockade, (2) calculating the mean response blockade across the plateau defined by this current and all higher currents sampled, and (3) dividing each curve by this mean plateau response blockade. When the normalized curves from all units were considered together, $25 \mathrm{nA}$ AP5 reduced auditory responses by a mean of $85 \%$ of the maximum attainable amount, and 40 nA AP5 reduced responses by a mean of $97 \%$ of the maximum (Fig. $3 B$ ). These results indicate that the standard current levels of AP5 produced a near-saturating blockade of the NMDA receptors involved in auditory transmission, at least for units near the tip of the iontophoresis electrode.

The same protocol was used to measure dose-response curves for CNQX blockade of auditory responses in ICx (Fig. 3C). Unlike AP5, CNQX produced dose-response curves of various shapes. Curves in which response blockade increased monotonically to a stable plateau were observed in only three of nine units tested; four of nine units showed monotonically increasing blockade that failed to saturate by $80 \mathrm{nA}$; and two of nine units showed nonmonotonic curves where responses declined and then increased again as current levels were increased above 25 nA. Because of the variety of curve shapes, we could not conclude that the standard ejection currents of CNQX always resulted in a maximal blockade of auditory responses. However, 25 and $40 \mathrm{nA}$ CNQX did, on average, produce blocks that approached the maximum mean block, when data were merged across all units.

\section{Effect of AP5 and CNQX on auditory tuning}

It is important to show that response blockade produced by AP5 and CNQX reflects an overall reduction in auditory respon- 

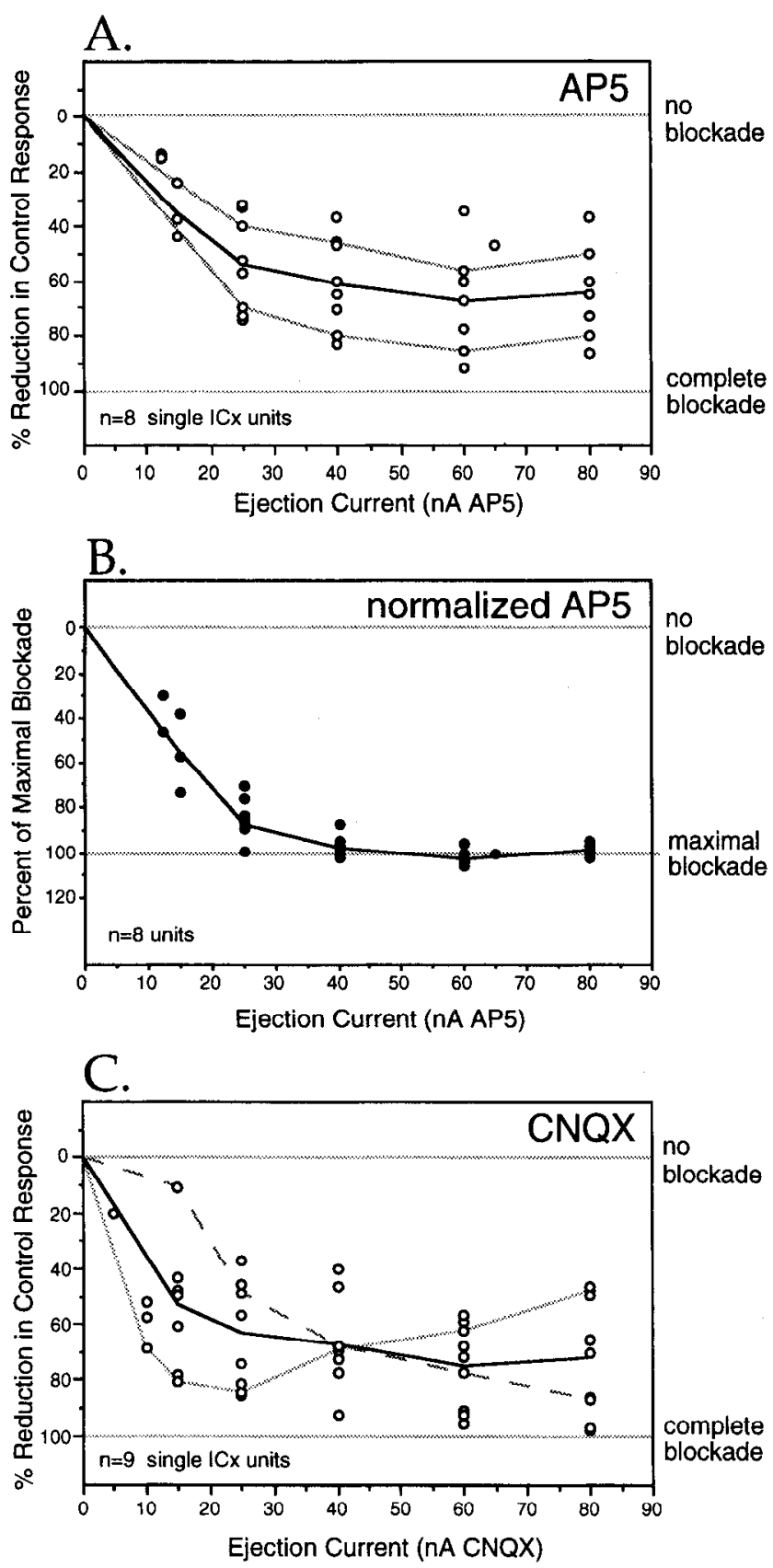

Figure 3. Dose response for the antagonism of auditory responses by AP5 and CNQX. A, Effect of AP5 ejection currents on auditory responses at eight ICx single-unit sites. The cffect was quantified for each unit separately by calculating the percentage reduction from control levels produced by AP5 at each current tested. Curves for two units are shown in gray; similar curves were obtained at the other six sites $(O)$, but are not connected for the sake of clarity. The mean effect for all eight units is indicated by the black curve. $B$, Normalization of AP5 dose-response curves to determine at which current level, on average, maximal blockade occurred. Dose-response curves from $A$ were normalized so that $100 \%$ represented maximal blockade for each unit (see Materials and Methods). The average response blockade produced by 40 nA AP5 was $97 \%$ of the maximal blockade, and that produced by $25 \mathrm{nA}$ was $85 \%$ of the maximal blockade. $C$, Effect of CNQX ejection currents on auditory responses of nine ICX single-unit sites. Response blockade that asymptoted by $80 \mathrm{nA} \mathrm{CNQX}$ was observed at only three of nine sites. At four sitcs, blockadc incrcased monotonically but failed to saturate by $80 \mathrm{nA}$ CNQX (e.g., dashed gray line). At two sites, blockade was a nonmonotonic function of CNQX ejection current (e.g., solid gray line.) The mean effect for all nine sites is indicated by the black curve. siveness and not a pharmacologically induced shift in the tuning of units to either ITD, ILD, or frequency (Fig. 4). This consideration is particularly relevant in these subdivisions of the IC, where auditory responses result from local integration of inputs representing different values of binaural localization cues and different frequency channels. Tuning for ITD, ILD, and frequency were assessed at five multiunit ICx sites before and during iontophoresis of $40 \mathrm{nA}$ AP5. Best ITD, best ILD, and best frequency changed no more than $3.4 \mu \mathrm{sec}(n=8), 1.4 \mathrm{~dB}$ $(n=6)$, and $0.5 \mathrm{kHz}(n=4)$, respectively, between control tuning curves and curves collected during AP5 application. Widths of tuning curves also remained relatively constant with AP5 iontophoresis, declining an average of only $6 \%$ for ITD curves and $13 \%$ for ILD curves. Frequency tuning curves, however, did narrow significantly (paired $t$ test, $p<0.05$ ), with widths declining by an average of $0.9 \mathrm{kHz}$, or $30 \%$ of control width.

Like AP5, CNQX also produced a uniform blockade of auditory responses (Fig. 4, bottom row). CNQX iontophoresis caused peaks of tuning curves at $5 \mathrm{ICx}$ multiunit sites to shift by no more than $5 \mu \mathrm{sec}$ (ITD), $4.1 \mathrm{~dB}$ (ILD), or $0.6 \mathrm{kHz}$ (frequency). Widths of ITD and ILD tuning curves also remained constant, broadening by an average of $5.1 \%$ from control widths for ITD curves and $0.5 \%$ for ILD curves. Frequency tuning curves tended to narrow with CNQX iontophoresis, with widths declining an average of $0.6 \mathrm{kHz}$, or $24 \%$ of mean control width; however, this trend was not statistically significant (paired $t$ test, $p>0.05$ ). Together, these data indicate that blockade of responses to stimuli at a unit's best ITD and best ILD represented an overall reduction in auditory responsiveness.

\section{Representative effect of AP5 in the ICX and lateral shell}

AP5 produced very different effects on auditory responses in the ICx and lateral shell. Representative examples are shown in Figure 5. At each site, single-unit responses to an auditory stimulus presented every $2 \mathrm{sec}$ were measured during control periods and periods of drug iontophoresis. At the ICx site shown in Figure $5 A$, low AP5 ejection currents (10 nA and $20 \mathrm{nA}$ ) reversibly reduced auditory responses, while iontophoresis of pH-matched saline solution (pH CTL) failed to affect responses. At this site, like many others in the ICx, AP5 produced a nearcomplete blockade of auditory-evoked spikes. This blockade can be attributed to a specific action of AP5, rather than an effect of ejection current or $\mathrm{pH}$, since iontophoresis of the $\mathrm{pH}$ matched control solution did not itself affect responses. In the lateral shell, in contrast, AP5 had only a small effect on auditory responses, even when applied at $40 \mathrm{nA}$, as shown for the representative sitc in Figure $5 B$. CNQX significantly reduced auditory responses at this site, as it did at all lateral shell sites, showing that the synapses mediating auditory transmission were indeed accessible to iontophoresed drugs.

This apparent difference in the pharmacology of ICX and lateral shell units was verified by recording from a large population of single and multiple units in the two subdivisions. At each site, the magnitude of auditory response blockade was calculated for each drug applied, by subtracting the mean of the final 40 auditory responses collected during drug application from the mean of the final 40 responses collected during the control period, and expressing this difference as a percentage of the mean control response. The significance of the drug effect was determined as detailed in Materials and Methods. Two steps were taken to ensure that observed differences in APS and CNQX response blockade were due to real pharmacological differences 

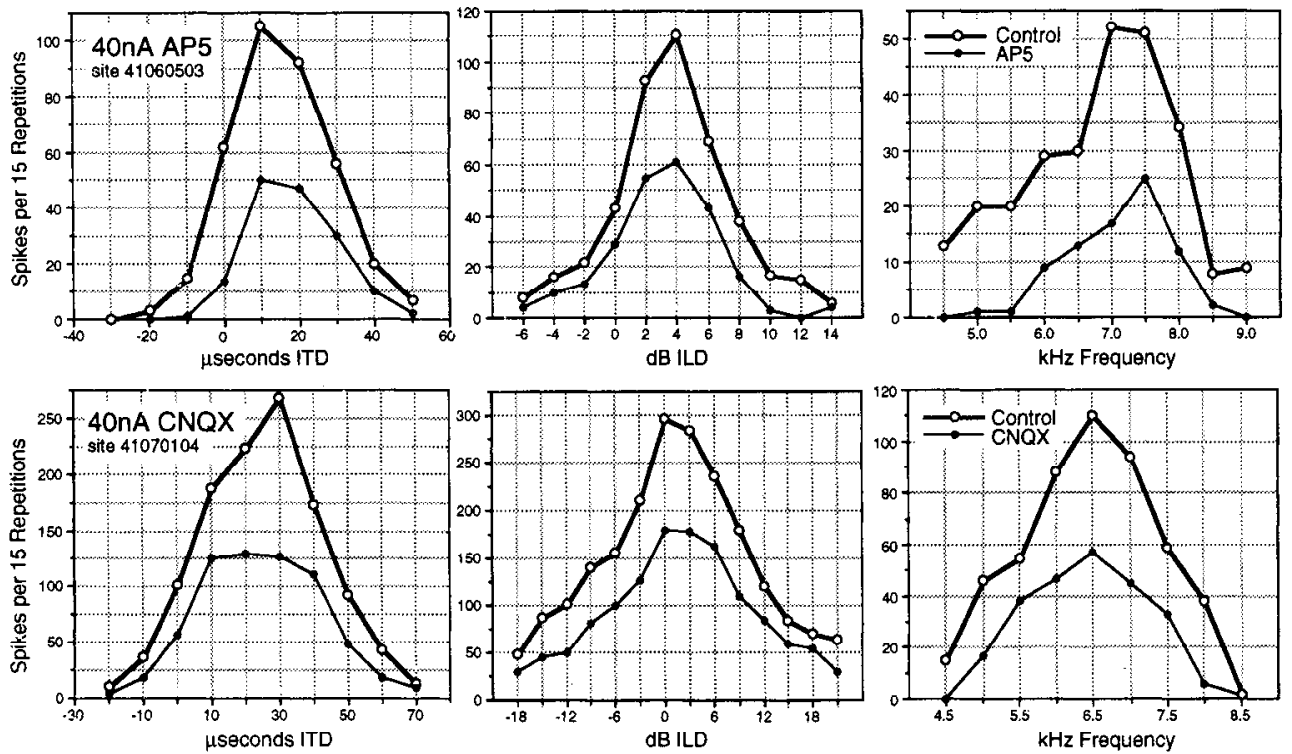

between sites, and not to failures of the iontophoresis electrodes to deliver drugs in a reproducible manner. First, the performance of the AP5 barrel was verified after every site at which AP5 failed to reduce responses significantly. This was accomplished by iontophoresing AP5 at a subsequent site in the same penetration, and demonstrating that auditory responses or re-

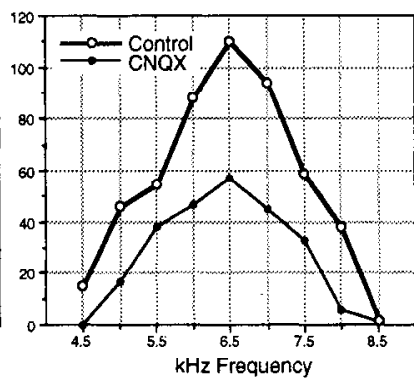

Figure 4. Effect of AP5 and CNQX on ICx unit tuning to binaural localization cues and to frequency. For each curve, points denotc the total response to 15 stimulus presentations. Top row, AP5 (40 nA) uniformly reduced responses to auditory stimuli of varying ITD (left), ILD (middle), and frequency (right). Negative on the ITD axis indicates left ear leading ITDs; negative on the ILD axis indicates left ear greater ILDs. For this unit, tuning curve peaks varied with AP5 iontophoresis by only $3.4 \mu \mathrm{sec}$ in ITD, $0.2 \mathrm{~dB}$ in ILD, and 0.8 $\mathrm{kHz}$ in frequency. Bottom row, CNQX $(40 \mathrm{nA})$ also reduced auditory responses uniformly to stimuli of varying ITD, ILD, and frequency. Tuning curve peaks for this unit varied with CNQX by $0 \mu \mathrm{sec}$ in ITD, $0.3 \mathrm{~dB}$ in ILD, and $0.1 \mathrm{kHz}$ in frequency.

sponses to iontophoresed NMDA were significantly reduced at that site. Second, ICX and lateral shell sites were recorded in alternate penetrations during some experiments, in order to verify that differences in response blockade between the subdivisions were not due to changes in drug delivery that may occur over the course of the recording session.

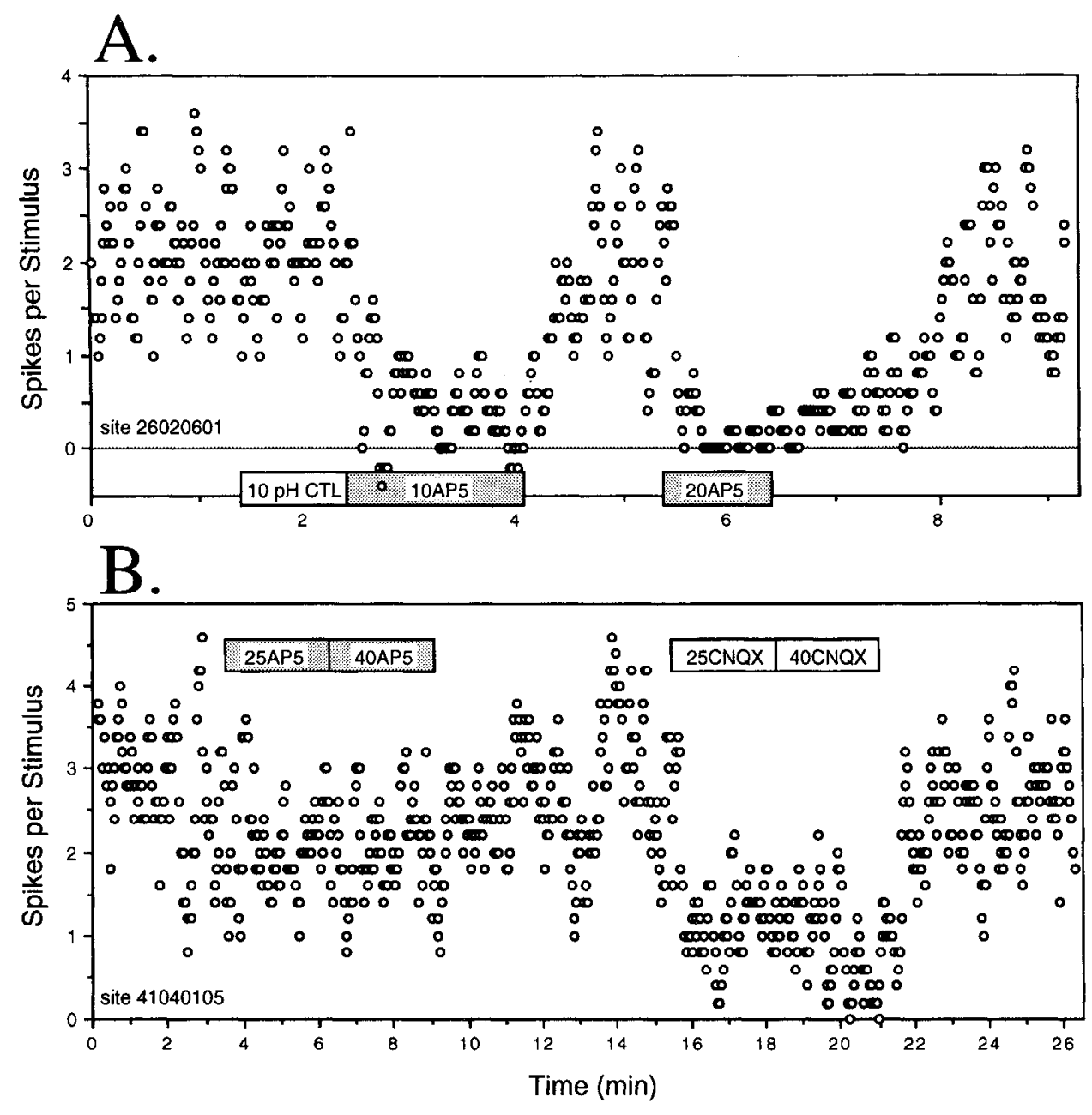

Figure 5. Examples of the effect of AP5 on auditory responses in the ICx and lateral shell. $A$, AP5 potently and reversibly blocked auditory responses of an ICx single unit. Each point represents the number of spikes evoked over baseline by a single noise stimulus presented every 2 sec. Responses were smoothed with a five-point moving average. This cell fired a mean of 2.2 spikes per stimulus during the control period, and responses were not affected by iontophoresis of $10 \mathrm{nA}$ of a $\mathrm{pH} 7.0$ control solution ( $p H C T L$ ). However, responses were potently antagonized by $10 \mathrm{nA}$ of a pH 7.0 AP5 solution from another electrode barrel (gray bar), reducing responses to a mean of 0.42 spikes per stimulus. During AP5 application, responses were reduced to a steady plateau level. $B$, The effect of AP5 was much smaller at this singleunit site in the lateral shell. Responses during AP5 iontophoresis were not significantly reduced from control levels ( $t$ test comparing the final 40 responses during AP5 iontophoresis with the final 40 control responses, $p>0.05$; see Materials and Methods). However, CNQX applied at the same current levels greatly reduced auditory responses $(t$ test, $p$ $<0.05$ ). 

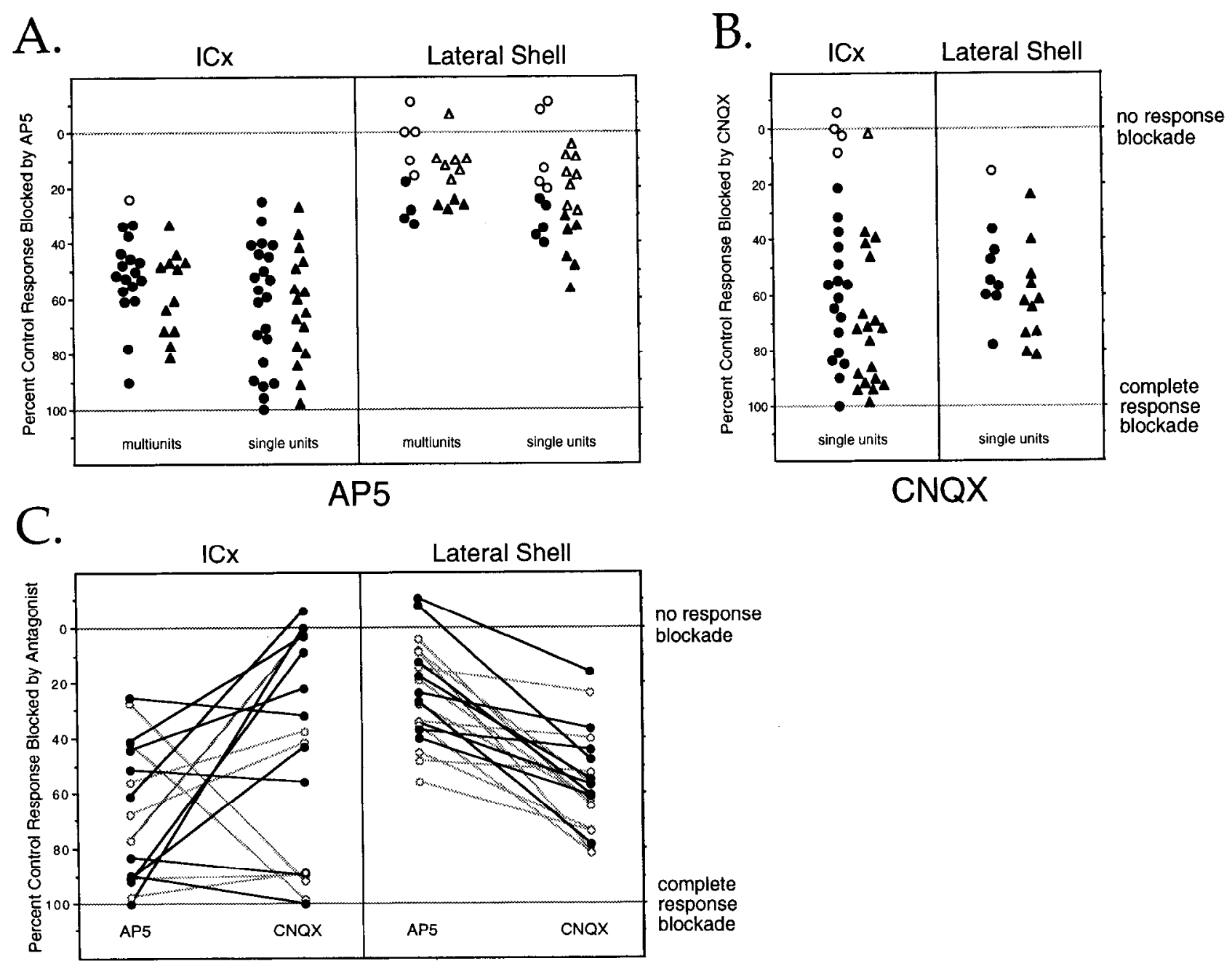

Comparison

Figure 6. Magnitude of response blockade produced by AP5 and CNQX for all ICx and lateral shell sites. $A$, Effect of AP5. Each circle denotes the response blockade produced at a single site by application of $25 \mathrm{nA}$ AP5, and each triangle, $40 \mathrm{nA}$ AP5. Some sites were tested at both current levels. Solid symbols indicate significant reduction of control responses ( $t$ test for data at individual sites; see Materials and Methods); open symbols indicate no significant effect. Left, Response blockade at all ICx sites. Right, Response blockade at all lateral shell sites. $B$, Effect of CNQX at singleunit sites. Conventions are as in $A$. Some units were tested at both current levels. $C$, Comparison of the effects of AP5 and CNQX on individual units. For 11 single units in each subdivision, the effects of AP5 and CNQX on auditory responses were measured sequentially. For each unit, the magnitude of auditory response blockade produced by each drug is plotted, and the values are connected by a line segment. A negative slope indicates that CNQX reduced auditory responses to a greater extent than did AP5; a positive slope indicates that AP5 had a greater effect. Solid circles and dark lines, $25 \mathrm{nA}$; open circles and gray lines, $40 \mathrm{nA}$.

\section{Effect of AP5 on ICX auditory responses}

AP5 was applied at a total of 26 multiunit sites in the ICx, and blocked auditory responses at all of them (Fig. $6 \mathrm{~A}$, left). On average, AP5 blocked $51.2 \pm 15.7 \%( \pm \mathrm{SD})$ of auditory-evoked spikes when applied at $25 \mathrm{nA}(n=18)$, and $57.8 \pm 15.2 \%$ of auditory-evoked spikes when applied at $40 \mathrm{nA}(n=12)$. An unpaired $t$ test comparing these two data sets showed that there was no effect of current level on response blockade $(p=0.26)$. This is consistent with the dose-response data indicating that both of these current levels produced near-maximal response blockade (Fig. $3 C$ ). The auditory response blockade produced by AP5 was statistically significant at every site tested, as measured by $t$ tests at individual sites, although at one site (open circle in Fig. $6 A$, left) the lower current level failed to produce a significant blockade of auditory responses. The higher current level significantly reduced responses at this site.
AP5 was also applied at 25 single-unit sites in the ICx, and its effects on these units mirrored its effects at multiunit sites. Seventeen single units were assayed using the standard recovery protocol, and eight were assayed as part of more extensive doseresponse protocols (see Materials and Methods). There was no effect of protocol on AP5 blockade (unpaired $t$ test: $25 \mathrm{nA}, p=$ $0.36 ; 40 \mathrm{nA}, p=0.78$ ), and therefore data gathered with the two protocols were considered together. On average, AP5 blocked $62.2 \pm 22 \%$ of auditory responses when applied at $25 \mathrm{nA}(n-$ 22 units), and $62.8 \pm 20 \%$ of auditory responses when applied at $40 \mathrm{nA}$ ( $n=16$ units). At several single-unit sites at which full recovery was demonstrated, AP5 blocked auditory responses completely. As was true for the multiunit recordings, the two standard current levels reduced auditory responses equally (unpaired $t$ test, $p=0.93$ ). Mean response blockade measured at single-unit sites was slightly greater than that at multiunit sites, probably because cells distant from the ionto- 
phoresis electrode were excluded during single-unit isolation. As a result, the synapses of a single unit might have been more likely than the synapses of multiple units to be subject to an effective dose of iontophoresed drug.

\section{Effect of AP5 on lateral shell auditory responses}

AP5 was applied to a total of 19 multiunit sites in the lateral shell (Fig. $6 A$, right). AP5 blocked multiunit auditory responses by an average of $13.8 \pm 15.4 \%$ when applied at $25 \mathrm{nA}(n=9)$, and by an average of $15.1 \pm 10.3 \%$ when applied at $40 \mathrm{nA}(n$ $=11$ ). The magnitude of response blockade produced by the two standard current levels was not significantly different (unpaired $t$ test, $p=0.83$ ). When the data were merged across current level, they formed a distribution whose mean was significantly different from no blockade (one-group $t$ test, $p=$ 0.0001 ), indicating that, on average, AP5 significantly reduced auditory responses at lateral shell multiunit sites. Unlike ICx auditory responses, lateral shell responses were significantly reduced from control levels at less than half the sites tested: significant response blockade, as measured by $t$ test at individual sites, was observed at only four of nine sites using $25 \mathrm{nA}$ and at only four of 11 sites using $40 \mathrm{nA}$.

AP5 was also applied at 14 single-unit sites in the lateral shell, and its effects on these units confirmed the observations made at multiunit sites. On average, AP5 blocked single-unit auditory responses by $19.3 \pm 18 \%$ when applied at $25 \mathrm{nA}$ and by 26.6 $\pm 27 \%$ when applied at $40 \mathrm{nA}$. The amount of response blockade produced by the two current levels was again not significantly different (unpaired $t$ test, $p=0.30$ ). Only half ( 5 of 10 units tested at $25 \mathrm{nA}$, and 7 of 14 units tested at $40 \mathrm{nA}$ ) of the lateral shell single units showed significant amounts of auditory response blockade, as measured by $t$ test at individual sites. At all of the single- and multiunit sites at which AP5 failed to reduce auditory responses significantly (Fig. 6A, right, open circles), statistically significant response blockade was obtained with 25 or $40 \mathrm{nA}$ CNQX iontophoresis, indicating that the synapses mediating auditory transmission were in fact accessible to drugs applied through the electrode.

\section{Comparison of the effect of AP5 between the ICX and lateral shell}

The magnitude of response blockade produced by AP5 was significantly smaller in the lateral shell than in the ICx, at both multi- and single-unit sites. At multiunit sites, the difference in blockade between the two subdivisions was statistically significant at each of the standard current levels considered separately (unpaired $t$ test: $25 \mathrm{nA}, p=0.0001 ; 40 \mathrm{nA}, p=0.0001$ ). In addition, data were merged across current levels to arrive at a single range of values representing AP5 response blockade in each subdivision. Data from the two current levels were merged by calculating a single value of response blockade for each unit tested ( $n=26$, ICx; $n=19$, lateral shell). If a unit was tested at only one current level, the response blockade measured at that level was used in the analysis; if a unit was tested at both current levels, the mean of the two response blockades was used. When the current levels were merged in this fashion, AP5 blocked auditory responses of ICx multiunit sites by $54.7 \pm 16 \%$, and blocked auditory responses of lateral shell multiunit sites by only $14.6 \pm 13 \%$.

The significant difference in AP5 response blockade between ICX and lateral shell units also held for the single-unit data. Merged across current levels as described for the multiunit data,
AP5 reduced auditory responses of ICx single units $(n=25)$ by a mean of $63.6 \pm 19.2 \%$ from control levels, and reduced responses of lateral shell single units $(n=14)$ by a mean of 24.5 $\pm 15.6 \%$ from control levels. The magnitude of response blockadc was significantly grcater in the ICX than in the lateral shell for the data merged across current levels, as well as for each current level considered individually $(t$ test, $p<0.0001$ for all cases).

To determine whether the difference in AP5 blockade between the ICx and lateral shell represented a real difference in the pharmacology of excitatory amino acid transmission between these two subdivisions, we performed two independent control experiments. First, the auditory response blockade produced by iontophoresis of CNQX at single-unit sites was compared between the two structures. Second, a number of sites were tested using the $\mathrm{A} / \mathrm{A}+\mathrm{C}$ protocol (see Materials and Methods), which enabled us to adjust the magnitude of response blockade produced by AP5 for possible site-to-site differences in the overall effectiveness of excitatory amino acid antagonists, using the metric denoted $A / A+C$. These control experiments addressed the possibility that a difference in accessibility of iontophoresed drugs to relevant synapses may exist between the two IC subdivisions, or that auditory transmission in the lateral shell may be substantially mediated through receptors other than excitatory amino acid receptors. The results of these experiments are presented in the next few sections.

\section{The effect of $C N Q X$ on single-unit auditory responses}

CNQX was applied at 24 single-unit sites in the ICX, using one or both of the standard current levels of 25 and $40 \mathrm{nA}$ (Fig. 6B). Data from half of the ICx units were tested with the standard recovery protocol; the other half were tested with the doseresponse protocol (see Materials and Methods). There was no effect of protocol on the magnitude of auditory response blockade (unpaired $t$ test, $p=0.13$ ), and therefore the data were combined for further analysis. In the $\mathrm{ICx}$, the auditory response blockade produced by CNQX varied widely from unit to unit. At the majority of units tested (17 of 21 units tested at $25 \mathrm{nA}$, 18 of 19 units tested at $40 \mathrm{nA}$ ), CNQX application significantly reduced responses from control levels, as determined by $t$ test at individual sites. When applied at $25 \mathrm{nA}, \mathrm{CNQX}$ reduced auditory responses by an average of $50.8 \pm 31 \%$ from control levels $(n=21)$. When applied at $40 \mathrm{nA}$, CNQX reduced responses by an average of $70.1 \pm 28 \%$ from control levels $(n=$ 19). Response blockade for units tested at the higher current level was significantly greater than the blockade for units tested at the lower current level (unpaired $t$ test, $p=0.04$ ). This indicated that CNQX, unlike AP5, did not produce its maximal effect by $25 \mathrm{nA}$.

CNQX was applied using the standard recovery protocol to 12 single units in the lateral shell. CNQX application significantly reduced auditory responses from control levels for every unit tested. Auditory responses of one of these units were not significantly blocked by $25 \mathrm{nA} \mathrm{CNQX}$; however, responses were blocked by $40 \mathrm{nA}$ CNQX at this site. Applied at $25 \mathrm{nA}$, CNQX reduced auditory responses of lateral shell single units by an average of $50.6 \pm 18 \%$ from control levels $(n=9)$. Applied at $40 \mathrm{nA}, \mathrm{CNQX}$ reduced responses by an average of $61.0 \pm 18 \%$ from control levels $(n=11)$. The distributions of response blockade at the two current levels were not significantly different from one another (unpaired $t$ test, $p=0.20$ ).

Because the two current levels did produce different amounts 
Figure 7. Representative data obtained using the $\mathrm{A} / \mathrm{A}+\mathrm{C}$ protocol at sites in the ICx $(A)$ and lateral shell $(B)$. Each circle denotes the number of spikes elicited by a single noise stimulus, smoothed with a five-point running averagc. Stimuli were repeated every $2 \mathrm{sec}$ for a period of $15 \mathrm{~min}$. After control responses were measured, AP5 was iontophoresed until responses achieved a steady plateau level. CNQX was then also ejected at the same current level as the AP5. The final 40 responses for control, AP5, and combined AP5 and CNQX application are indicated by the graybars; the dark lines denote the mean response during each of these periods. The ratio of response blockade from control levels during AP5 application to the response blockade from control levels during combined AP5 and CNQX application was defined as the $\mathrm{A} / \mathrm{A}+\mathrm{C}$ metric (see Materials and Methods). $A$, AP5 reduced responses at this ICx site by $76 \%$ of the total blockade produced by combined AP5 and CNQX application. $B$, AP5 did not significantly reduce responses at this lateral shell site (ANOVA with Tukey procedure, $p>$ 0.05 ). The small reduction that was apparent with AP5 application accounted for only $14 \%$ of the total auditory response blockade produced by combined AP5 and CNQX application.
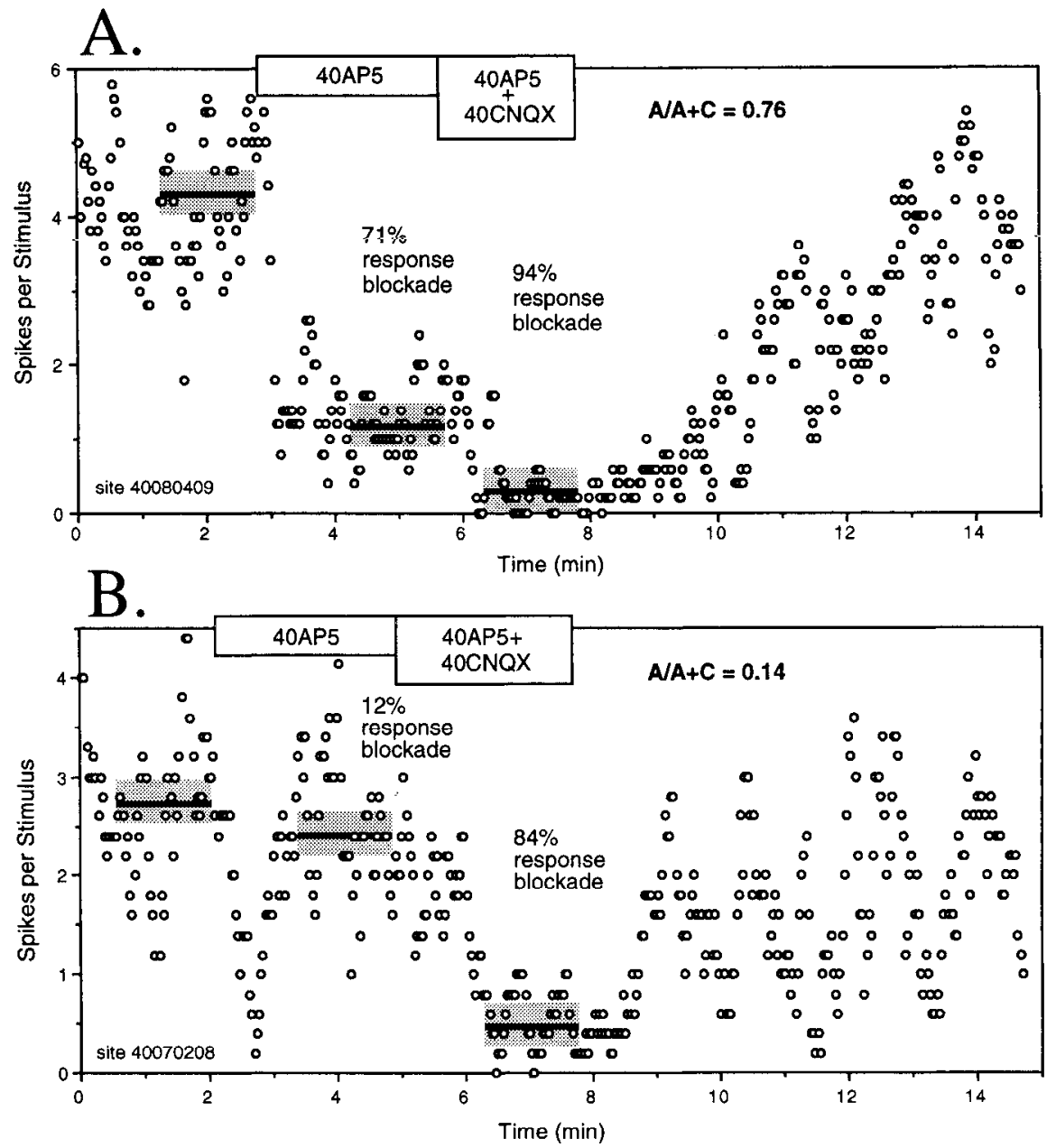

of response blockade in the ICx, comparisons between the ICx and lateral shell were made separately for each CNQX current level. The average response blockade produced by $25 \mathrm{nA} \mathrm{CNQX}$ differed by only $0.2 \%$ between the subdivisions; the average blockade produced by $40 \mathrm{nA} C \mathrm{NQX}$ was only $9.1 \%$ greater in the ICx than the lateral shell. Neither of these differences was significant (unpaired $t$ test: $25 \mathrm{nA}, p=0.99 ; 40 \mathrm{nA}, p=0.31$ ). Thus, CNQX blocked auditory responses equally well in both subdivisions, unlike AP5, which blocked responses significantly more in the ICx than the lateral shell.

The relative effects of AP5 and CNQX on auditory responses in the ICx and lateral shell were compared directly at 11 singleunit sites in each subdivision by scquentially applying AP5 and CNQX, with an intervening recovery period, at each site (Fig. $6 C$ ). In the ICx, AP5 had a greater effect than CNQX on the auditory responses of six of 10 units tested at $25 \mathrm{nA}$, and five of seven units tested at $40 \mathrm{nA}$. At $25 \mathrm{nA}$, AP5 reduced responses from control levels by a mean of $37 \%$ more than did CNQX. At $40 \mathrm{nA}$, the two drugs produced the same amount of response blockade, on average, due to increased CNQX effects on some units at the higher current level. For all 11 lateral shell units, in contrast, CNQX had a greater effect on auditory responses than did the same current level of AP5 (lines with a negative slope in Fig. $6 C$ ). CNQX blocked control responses by an average of $34 \%$ more than did AP5 at $25 \mathrm{nA}$, and by an average of $29 \%$ more than did AP5 at 40 IIA. In addition, CNQX sig- nificantly reduced responses of each of the five lateral shell units whose responses were not affected by AP5. These data indicate that AP5 tended to have a greater effect than CNQX on auditory responses in the ICx, while the converse was true in the lateral shell.

\section{Normalization of AP5 blockade using the $A / A+C$ protocol}

The second method for determining whether the difference in AP5 blockade between the ICx and lateral shell was due to a real difference in excitatory amino acid pharmacology was to normalize the response blockade produced by AP5 for possible site-to-site differences in the effectiveness of AP5 and CNQX. This was done by applying the $\mathrm{A} / \mathrm{A}+\mathrm{C}$ protocol (see Materials and Methods) to $14 \mathrm{ICx}$ and 16 lateral shell multiunit sites. In this protocol, illustrated in Figure 7, control responses were measured, and then 25 or $40 \mathrm{nA}$ AP5 was applied, and responses were allowed to fall to a steady plateau level. CNQX was then ejected at the same current level along with the AP5. Responses were again allowed to fall to a plateau level, after which both drugs were retained and recovery was verified. The ratio of response blockade during AP5 application to blockade during simultaneous AP5 and CNQX ejection was calculated as the $\mathrm{A} / \mathrm{A}+\mathrm{C}$ metric.

Representative data obtained using the $\mathrm{A} / \mathrm{A}+\mathrm{C}$ protocol are shown in Figure 7. At the ICx site (Fig. 7A), AP5 iontophoresis alone blocked a large fraction of control auditory responses. 

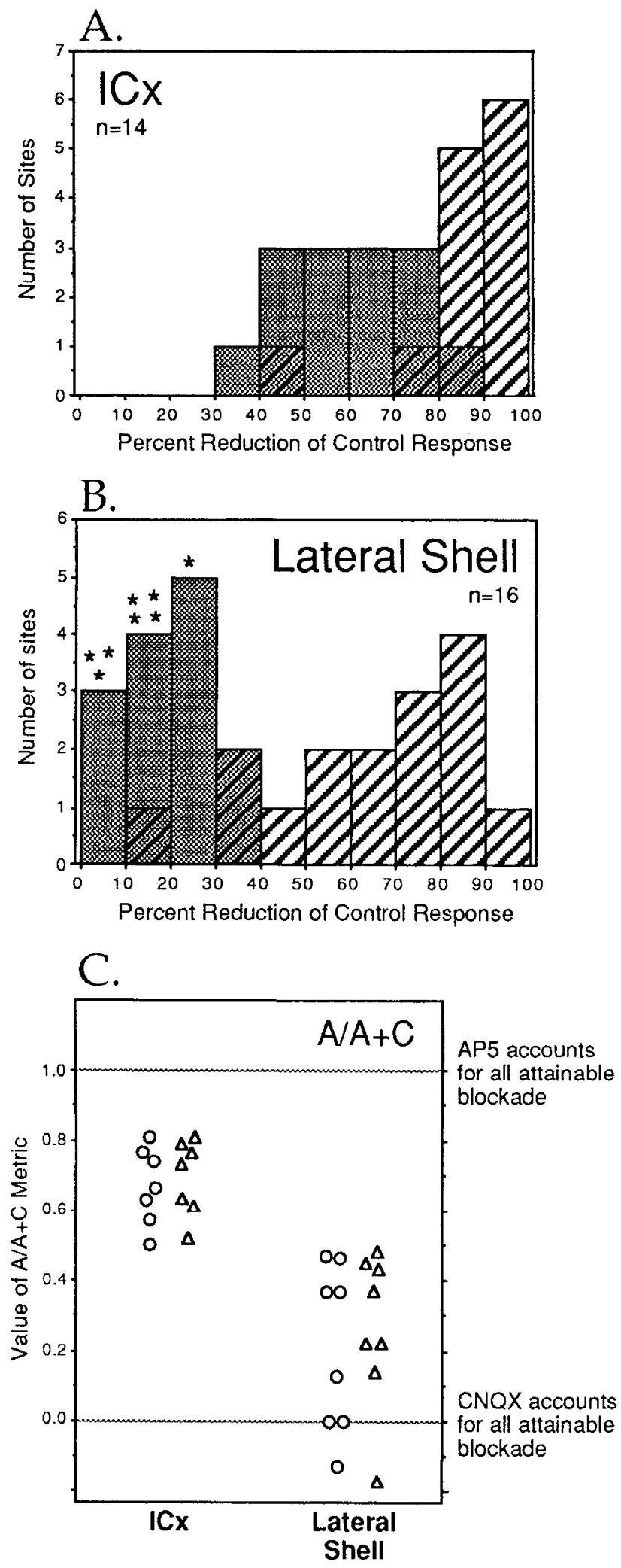

Figure 8. Results of the $\mathrm{A} / \mathrm{A}+\mathrm{C}$ protocol for all sites in the ICx $(A)$ and lateral shell $(B)$. Gray bars indicate the magnitude of response blockade produced by AP5. Hatched bars indicate the magnitude of response blockade produced by combined application of AP5 and CNQX. On the ordinate, 0 indicates no blockade of responses, and 100 indicates complete response blockade. Application of AP5 alone significantly reduced responses from control levels at all sites except for eight in the lateral shell (ANOVA with Tukey procedure); these eight are indicated by stars. Combined AP5 and CNQX application reduced responses
Although simultaneous ejection of CNQX further reduced responses, the blockade produced by AP5 accounted for the majority of the total blockade produced by combined AP5 and CNQX ejection, and thus the value of the $A / A+C$ metric was high (0.76). In contrast, at the lateral shell site (Fig. $7 B$ ), the blockade produced by AP5 was small, and the addition of CNQX reduced responses greatly from their levels under AP5 alone. Thus, the blockade produced by AP5 accounted for only a small fraction of the blockade produced by combined AP5 and CNQX, and the value of the $\mathrm{A} / \mathrm{A}+\mathrm{C}$ metric was low (0.14).

A similar pattern held true for all units studied (Fig. 8). Data were merged across current levels, because there was no significant effect of current level on the magnitude of blockade produced either by AP5 alone or by combined AP5 and CNQX in either subdivision. In the ICx $(n=14$; Fig. $8 A)$, AP5 consistently reduced control responses by large amounts (gray bars). Combined application of AP5 and CNQX further reduced responses (hatched bars). At all but one site, the addition of CNQX significantly reduced responses from their levels during AP5 application alone (ANOVA with Tukey procedure on data from individual sites; see Materials and Methods). In the lateral shell ( $n=16$; Fig. $8 B$ ), AP5 reduced responses by only small amounts, and at half the sites, indicated by stars, these reductions from control levels were not significant. However, combined application of AP5 and CNQX produced significant response blockade at cvery sitc tested, including those at which AP5 alone failed to block responses significantly.

The $\mathrm{A} / \mathrm{A}+\mathrm{C}$ metric was computed for each $\mathrm{ICx}$ and lateral shell site (Fig. 8C). There was no effect of current level on the $\mathrm{A} / \mathrm{A}+\mathrm{C}$ metric in either of the two subdivisions, and therefore the data were merged across current level for further analysis. For the $14 \mathrm{ICx}$ sites, the metric averaged $0.68 \pm 0.11$, and for the 16 lateral shell sites, the metric averaged $0.24 \pm 0.22$. These distributions were significantly different from each other (unpaired $t$ test, $p=0.0001$ ). The difference between subdivisions was also significant when the two current levels were analyzed separately (unpaired $t$ test, $p=0.0004$ for each current level). Therefore, these data indicate that the magnitude of response blockade produced by AP5 was greater in the ICX than the lateral shell, even when site-to-site differences in the effectiveness of iontophoresed AP5 and CNQX were adjusted for.

Data gathered with the $\mathrm{A} / \mathrm{A}+\mathrm{C}$ protocol also showed that simultaneous AP5 and CNQX application was an extremely effective method of blocking auditory responses in both the ICX and lateral shell (Fig. $8 A, B$, hatched bars). In addition to the sites tested with the $\mathrm{A} / \mathrm{A}+\mathrm{C}$ protocol, four $\mathrm{ICx}$ sites and two lateral shell sites were tested with combined AP5 and CNQX application using the standard recovery protocol. At every site tested, combined AP5 and CNQX application significantly reduced auditory responses from control levels (ANOVA with Tukey procedure on $\mathrm{A} / \mathrm{A}+\mathrm{C}$ sites, and $t$ test on standard recovery sites, $p<0.05$ ). In the ICx, $25 \mathrm{nA}$ each of AP5 and CNQX reduced auditory responses by an average of $77.6 \pm$ $16.6 \%$ from control levels $(n=9)$; when applied at $40 \mathrm{nA}$ each, responses were reduced by $89.6 \pm 9.2 \%$ from control levels $(n$

significantly more than AP5 application alone at every site tested excep for one in the ICx (ANOVA with Tukey procedure). $C$, Values of the $\mathrm{A} / \mathrm{A}+\mathrm{C}$ metric compared between the ICx and lateral shell. $0,25 \mathrm{nA}$; $\triangle, 40 \mathrm{nA}$. Each site was tested at only one dose. In the ICx, the metric averaged $0.68 \pm 0.11( \pm \mathrm{SD})$; in the lateral shell, $0.24 \pm 0.22$. 
A.

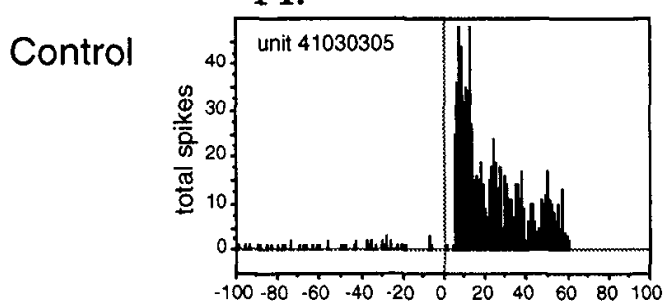

AP5

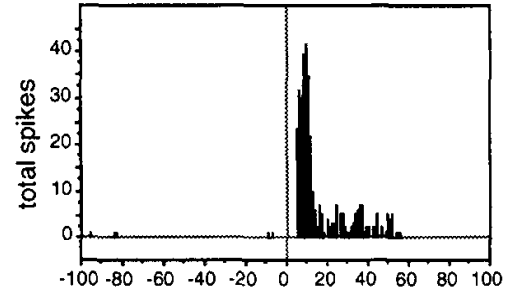

B.
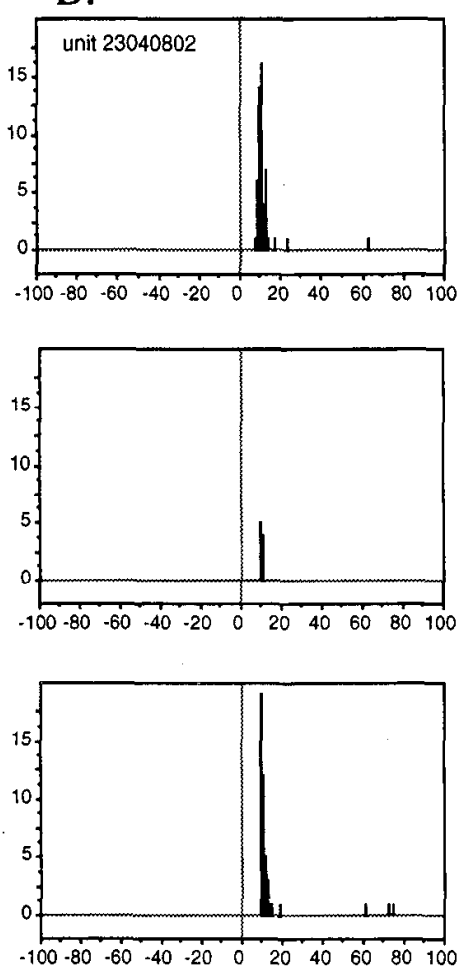

C.
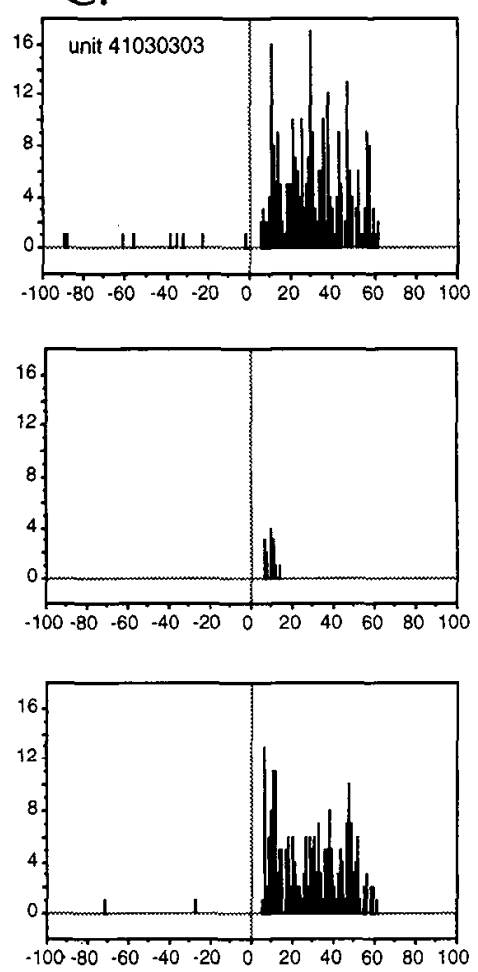

Peristimulus Time (msec)

Figure 9. AP5 reduced auditory responses of single ICx units with phasic-tonic, phasic, and tonic response patterns. Each peristimulus time histogram (PSTH) shows the average spike train elicited by 60 or 80 repetitions of a 50 msec broad-band stimulus at best ITD and best ILD, 20 $\mathrm{dB}$ above average threshold. The stimulus begins at time 0 . Ordinate units are total spikes across all responses. AP5 was applied at a current of $25 \mathrm{nA}$ for all units. $A$, Unit with a phasic-tonic response. Each PSTH represents 80 stimulus repetitions. Spikes late in the response are blocked more than spikes occurring early in the response. $B$, Unit with a phasic response profile. Each PSTH represents 80 stimulus repetitions. $C$, Unit with a tonic response profile. Each PSTH represents 60 stimulus repetitions.

=9). In the lateral shell, $25 \mathrm{nA}$ each of AP5 and CNQX reduced responses by an average of $68.7 \pm 29.3 \%$ from control levels $(n=8)$; when applied at $40 \mathrm{nA}$ each, responses were reduced by $54.2 \pm 17.7 \%$ from control $(n=10)$. The effect of current level was not significant in either subdivision (unpaired $t$ test: ICX, $p=0.08$; lateral shell, $p=0.28$ ), and therefore a comparison of the magnitude of response blockade between the two subdivisions was performed by merging the data across current levels. When data from both current levels were considered together, AP5 + CNQX reduced auditory responses by an average of $83.6 \pm 14.4 \%$ from control levels in the $\mathrm{ICx}(n=18)$, and by $61.7 \pm 23.7 \%$ from control levels in the lateral shell $(n$ $=18$ ); this difference was significant (unpaired $t$ test, $p=0.002$ ).

\section{Effect of AP5 on firing pattern of ICX single units}

Single ICx units responded to broad-band noise bursts with either phasic, phasic-tonic, or tonic responses (Fig. 9). Units were classified into one of these three groups on the basis of poststimulus time histograms (PSTIIs) constructed from responses to at least 60 stimulus presentations. When classifying units, off responses were eliminated by restricting the analysis to spikes occurring in the first $50 \mathrm{msec}$ of the response. Responses with more than $90 \%$ of total spikes occurring within the first $20 \mathrm{msec}$ after stimulus onset were classified as phasic responses, responses with $40-90 \%$ of spikes occurring within this time window were classified as phasic-tonic responses, and responses with less than $40 \%$ of spikes occurring in this time window were classified as tonic responses. The classification is somewhat arbitrary since a continuous range of firing patterns, from purely phasic to purely tonic, was observed across the population of units. Using these criteria, however, the majority of ICx single units in this study ( 32 of 50 ) exhibited phasictonic responses to broad-band noise. Responses of all these types were blocked potently by AP5 applied at 10-25 nA (Fig. 9).

We had observed early in this study that for units with phasictonic or tonic responses, AP5 appeared to block spikes occurring late in the response train (late spikes) more effectively than it blocked spikes occurring early in the response train (early spikes). This pattern is evident in the responses shown in Figure 9, $A$ and $C$. Because of this observation, the effect of AP5 on the time course of ICx responses was examined systematically for 26 single units. Units with phasic-tonic and tonic responses were grouped together for this analysis, since both of these response types had a large proportion of late spikes. Units with phasic responses were considered as a separate group. For each unit in a group, a PSTH was constructed from 60-120 control responses and the same number of responses collected during application of $25 \mathrm{nA}$ AP5. The PSTHs were normalized to represent responses from 100 stimulus repetitions each, aligned by stimulus onset, and then summed with PSTHs from other 
A.

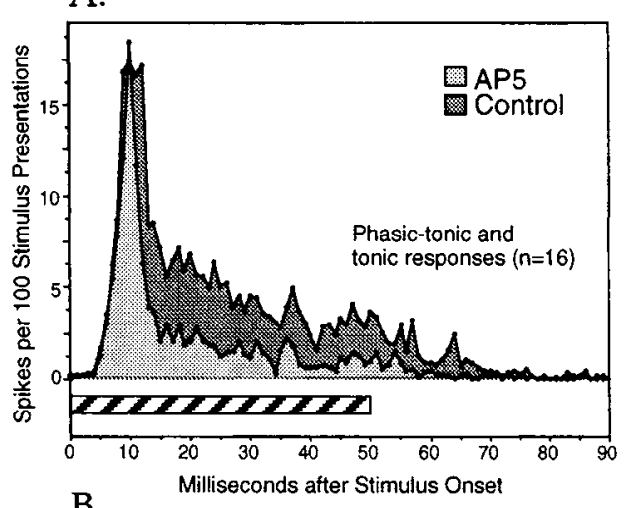

B.

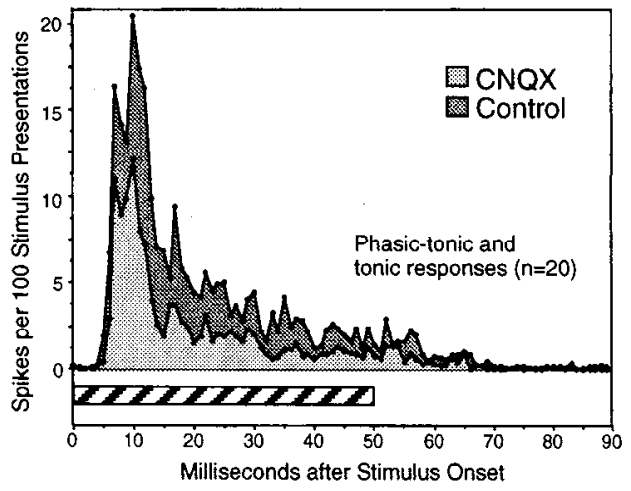

C.

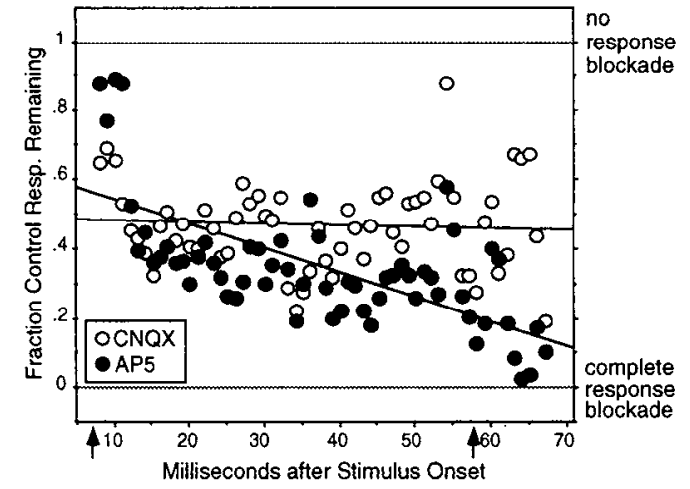

Figure 10. Effects of AP5 and CNQX on the time course of phasic-tonic and tonic responses. Composite PSTHs (shaded curves) were calculated by summing PSTHs from all ICx units with phasic-tonic and tonic responses and to which AP5 $(n=16)$ or CNQX ( $n=20)$ had been applied. Individual unit PSTHs were derived from responses to 60-120 stimulus repetitions, normalized to contribute equally to the composite PSTHs, and aligned by stimulus onset (see Materials and Methods). Dark shading, composite PSTH for responses during control conditions; light shading, composite PSTH for responses of the same units during application of $25 \mathrm{nA}$ AP5 $(A)$ or 15-25 nA CNQX $(B)$. The hatched bar represents the duration of the sound stimulus. $A$, AP5 blocked few spikes on the rising phase of the composite response, and blocked a greater proportion of spikes occurring late in the composite response. $B, \mathrm{CNQX}$ blocked spikes throughout the composite response, including spikes on the rising phase. $C$, Fraction of control response remaining during AP5 (๑) and CNQX $(0)$ application. The values were computed at $1 \mathrm{msec}$ intervals based on the data in the composite PSTHs shown in $A$ and $B$, as described in the text. Regression lines were fit to the data for the 50 msec period (arrows) beginning at the average latency $(7 \mathrm{msec}$ ). Response blockade by AP5 increased significantly over the time course of the response (slope $=-0.007$, $\left.r^{2}=0.33, p<0.001\right)$, whereas blockade by CNQX had no significant slope $\left(r^{2}=0.004, p>0.05\right)$.

units in the group into composite PSTHs representing average control responses and average responses during AP5 application (see Materials and Methods).

Examination of the composite PSTHs for 16 phasic-tonic and tonic units (Fig. 10A) revealed that spikes occurring in the initial $5 \mathrm{msec}$ of the average response were relatively unaffected by AP5, whereas spikes occurring later in the response were substantially suppressed. To quantify how response blockade varied over the time course of the response, response blockade was calculated at $1 \mathrm{msec}$ intervals after stimulus onset, by dividing the values from the composite AP5 PSTH by the values from the composite control PSTH. The resulting quotients were smoothed with a two-bin running average, and the data were fit by linear regression (Fig. 10C. solid circles). Data for the regression were limited to the interval between $7 \mathrm{msec}$ after stimulus onset (the average latency) and $57 \mathrm{msec}$ after stimulus onset, to exclude off responses. The results showed that the magnitude of response blockade increased significantly over the course of the response (slope $=-0.007, r^{2}=0.33$ ). The regression remained significant even when spikes occurring 7-10 msec after stimulus onset, which were particularly resistant to AP5 blockade, were excluded from the analysis.

The effect of CNQX on the time course of phasic-tonic and tonic responses was determined in the same manner (Fig. 10B). PSTH data was collected from responses of 20 single ICx units before and during iontophoresis of CNQX at 15-25 nA. These current levels were selected for analysis because they produced approximately the same overall magnitude of auditory response blockade as did the AP5 current level that was used for time course analysis (CNQX, 51\% blockade; AP5, 54\% blockade). Like AP5, CNQX blocked spikes late in the response train. Unlike AP5, however, CNQX also blocked a large proportion of the earliest spikes in the response (Fig. 10B). The variation of response blockade over the time course of the response was calculated from the composite PSTHs at $1 \mathrm{msec}$ intervals, in the same manner as was done for AP5. Data between 7 and 57 msec after stimulus onset were fit with a regression (Fig. 10C. open circles). Unlike AP5, CNQX blocked a constant proportion of spikes over the time course of the response (slope $=-0.001$, $\left.r^{2}=0.004\right)$. The slopes of the AP5 and the CNQX regression lines were significantly different $(p<0.05)$, as determined by an extension of the general linear test (see Materials and Methods). The time course analysis was repeated, for both AP5 and CNQX effects, using PSTHs that were aligned by response latency, rather than by stimulus onset, in order to verify that these results were independent of the method for calculating response 
Figure 11. Effect of AP5 on the time course of phasic responses. Data were analyzed and displayed as in Figure 10 for 10 units that displayed phasic responses. $A$, AP5 reduced spikes throughout phasic spike trains. $B$, To determine if response blockade increased with time after stimulus onset, the composite AP5 histogram in $A$ was divided by the control histogram, by the method described in the text. Data were fit with a regression for the time window between the average latency ( 7 $\mathrm{msec}$ ) and the time at which most of the response had subsided ( $30 \mathrm{msec}$ ) Response blockade by AP5 increased significantly with time after stimulus onset (slope $=-0.029, r^{2}=0.848$ ).
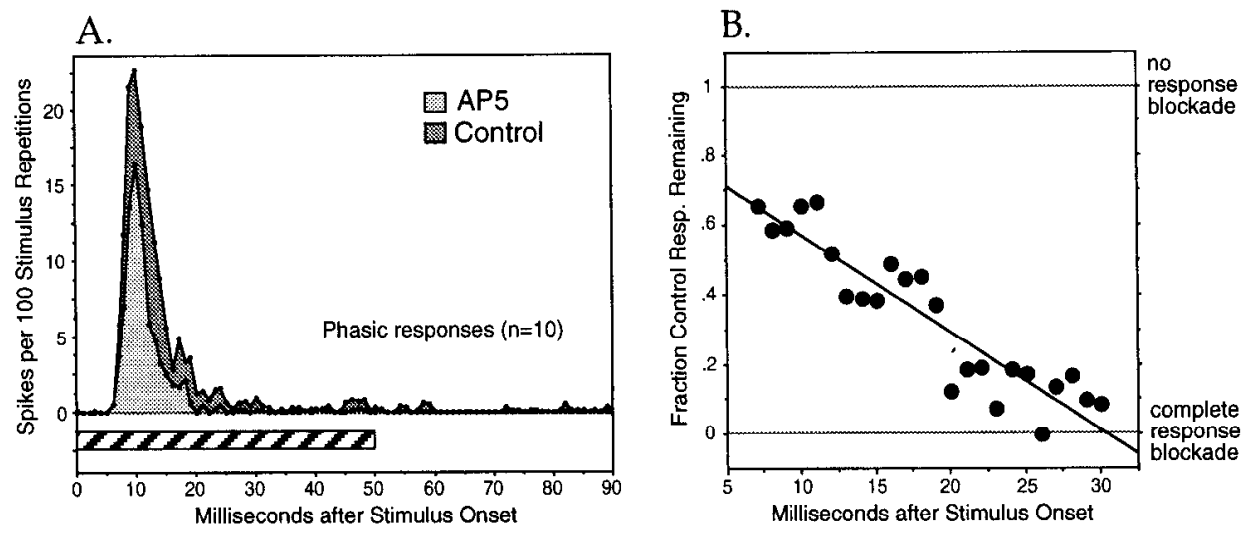

blockade. This analysis produced results identical to those described above.

For a group of 10 units with phasic responses, $25 \mathrm{nA} \mathrm{AP5}$ produced a pattern of blockade with response time course similar to that observed for the phasic-tonic and tonic response group (Fig. 11A). Composite PSTHs were made as described for the phasic-tonic and tonic units, using PSTHs from individual phasic units aligned by stimulus onset. Response blockade was calculated from the values of the composite PSTHs, again at $1 \mathrm{msec}$ intervals. A regression was performed on the data between $7 \mathrm{msec}$ and $30 \mathrm{msec}$ after stimulus onset; $30 \mathrm{msec}$ was chosen as a cutoff because spikes occurring after this time point were rare among phasic units. Response blockade increased significantly with time after stimulus onset (Fig. 11B; slope $\left.=-0.029, r^{2}=0.848\right)$, indicating that AP5 blocked late spikes to a greater extent than early spikes for phasic units, despite the short duration of their responses.

A final, independent analysis demonstrated that the effect of AP5 on response time course was consistent from unit to unit. The mean time of arrival for all spikes occurring within the first $50 \mathrm{msec}$ of the response, postlatency, was computed for every ICx unit. Mean spike arrival time is an index that reflects the distribution of spikes within the response train (sce Materials and Methods). Two values of this index were computed for each unit: one value for responses collected under control conditions, and a second value for responses collected during drug application. The two values are plotted against one another in Figure $12 A$ for every unit sampled. AP5 reduced mean spike arrival time from control values for 24 of 26 units (solid circles below the diagonal line). This change in index value reflects a change in the distribution of spikes over the time course of the response, and not a change in response latency, because response latency itself was not affected by application of either AP5 or CNQX (data not shown). In contrast to the effect of AP5, CNQX reduced mean spike arrival time for only 12 of 24 units and increased mean arrival time for the other 12 units. The different effects of AP5 and CNQX on this index were summarized by calculating the distance of each point plotted in Figure $12 A$ from the line representing no change in the index. The distribution of these distances for each drug is shown in Figure 12B. The two distributions are significantly different (unpaired $t$ test, $p=$ 0.0001 ). The mean of the distribution for AP5 is significantly less than zero (single-group $t$ test, $p=0.0001$ ), indicating that AP5, on average, significantly decreased mean spike arrival time. The mean of the distribution for CNQX, on the other hand, is not significantly different from zero $(p=0.86)$, indicating that CNQX had no consistent effect on mean spike arrival time. Because a reduction in mean spike arrival time reflects a pref-
Figure 12. Effects of AP5 and CNQX on avcrage spikc arrival time for singleunit responses in the ICx. The average arrival time (see Materials and Methods) for spikes in the auditory response was computed for responses during control and drug conditions for each unit. Arrival times were measured in milliseconds after response latency. $A$, Average arrival time for control responses is plotted against average arrival time for responses during AP5 (๑) and CNQX (O) application. The line of slope $=1$ indicates no effect of drug application on average spike arrival timc. Points beneath the line indicate units for which drug application decreased average arrival time. $B$, Difference of each point in $A$ from the line of slope $=1$. Negative differences indicate that the drug decreased average arrival time; positive differences indicate that the drug increased average arrival time.
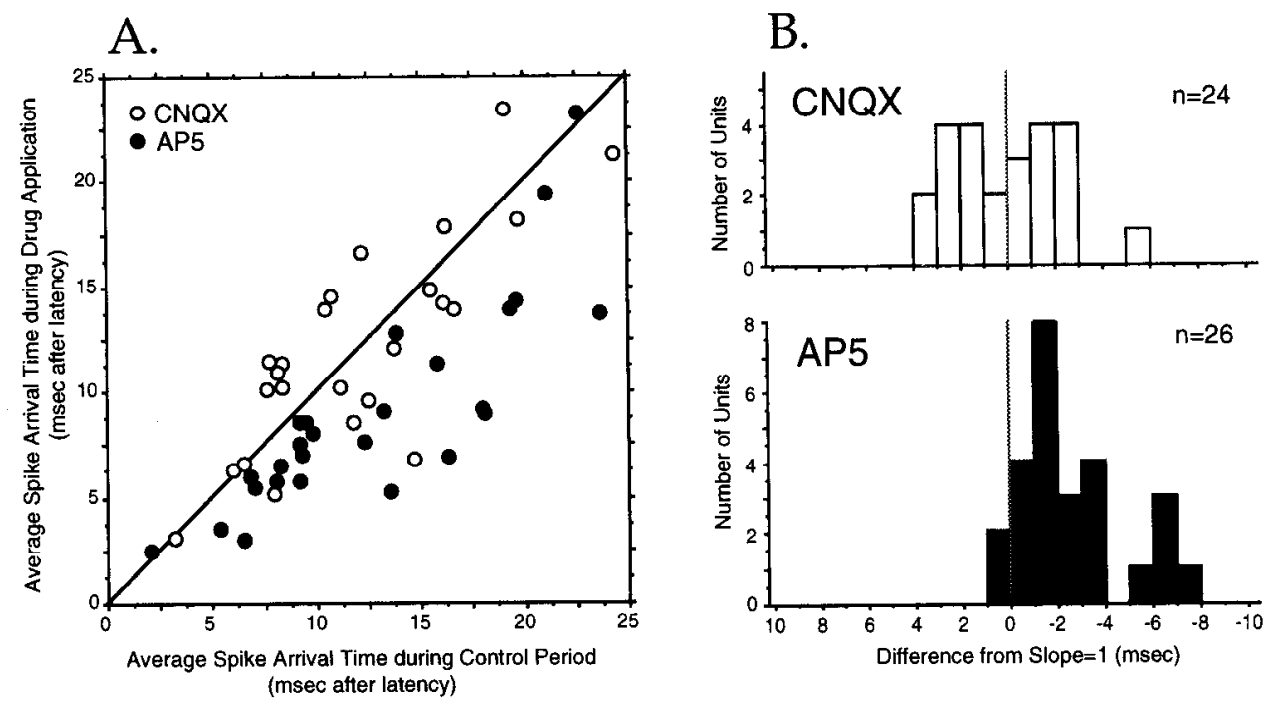

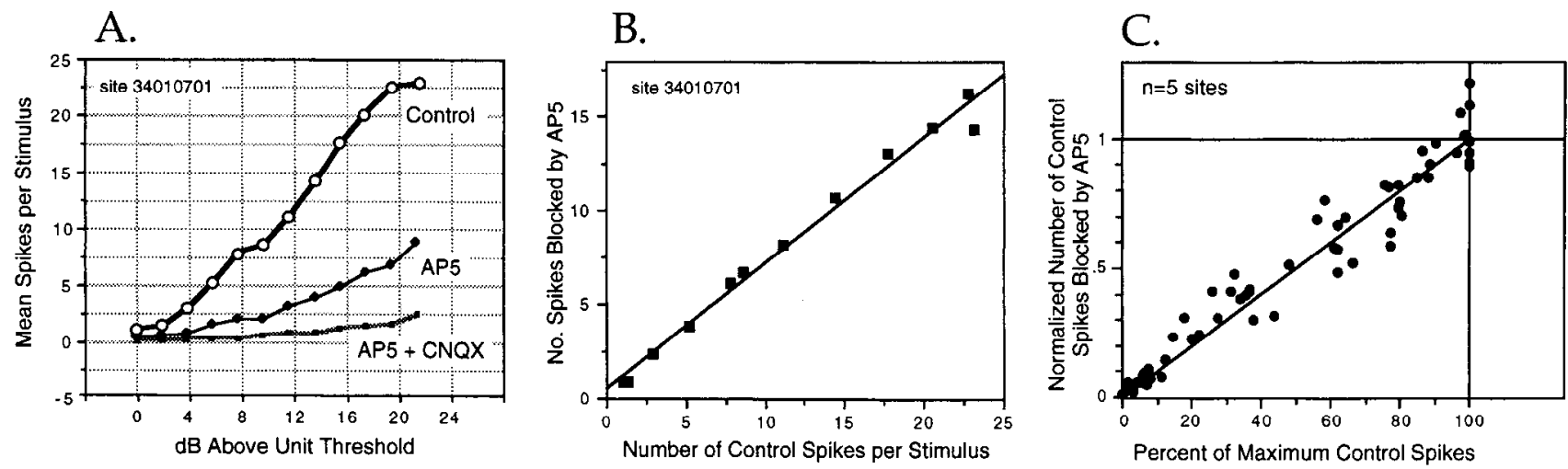

Figure 13. Effect of AP5 on responses of ICx units to stimuli of different sound intensity. One single-unit and four multiunit sites were tested with broad-band noise stimuli presented at best ITD and best ILD, and ranging in sound level from 0 to $18-23 \mathrm{~dB}$ above threshold. Responses to 20 repetitions of the series of levels were collected under control conditions and during application of $25 \mathrm{nA}$ AP5. $A$, Results from one multiunit site. Responses during simultaneous AP5 and CNQX iontophoresis are shown for comparison. $B$, Data from $A$, replotted to show that the number of control spikes blocked by AP5 was a constant proportion of the total number of spikes in the control response $\left(r^{2}=0.987\right)$. This analysis was performed for all five sites and all sites showed the same effect. $C$, Data, as in $B$, for each site were normalized by dividing control response magnitudes at each site by the maximum control response observed at that site, and by dividing the spikes blocked by AP5 by the quantity $m$. maximum control response $+b$, where $m=$ slope of the regression line and $b=$ the intercept. This normalization rotates each data set so that the regression line passes through the point $(1,1)$. No site showed any abrupt increase in the proportion of spikes blocked by AP5 with increasing response magnitude.

erential blockade of late spikes, this analysis demonstrates that AP5 preferentially blocked late spikes relative to early spikes in ICx responses, whereas CNQX, on average, blocked early and late spikes equally.

\section{The effect of $A P 5$ on responses to stimuli of varying sound intensity}

Because of the important implications of the NMDA receptor threshold for sensory computation (Daw et al., 1993) and synaptic modification (Madison et al., 1991), we chose to examine NMDA-dependent auditory responses in the ICx, to see if they exhibited any type of simple threshold behavior over the dynamic range of ICx neurons. Responses of one single-unit and four multiunit sites were collected in response to broad-band noise stimuli that varied over an $18-23 \mathrm{~dB}$ range of average binaural levels. The exact range of levels was selected at each site so that units responded weakly or not at all to the lowestlevel stimuli, maximally to the highest-level stimuli, and so that responses monotonically increased with sound levels in between. Level-response curves were constructed from responses to 20 repetitions of the stimulus set during a control period and during iontophoresis of $25 \mathrm{nA}$ AP5. If NMDA receptor currents exhibited a threshold behavior, one would expect that NMDA receptor currents would contribute less to weak responses and more to strong responses, and therefore that weak responses would be less potently antagonized by AP5 than strong responses.

Results obtained with this protocol at a representative site are shown in Figure 13A. Application of $25 \mathrm{nA}$ AP5 reduced the slope of the control level-response curve, and blocked responses to both the lowest and the highest level stimuli. The number of spikes blocked by AP5 was a linear function of the number of spikes in the original control response (Fig. 13B), indicating that AP5 blocked a constant percentage of spikes, regardless of whether the response was weak or strong. The same analysis was applied to the data from the other four sites (Fig. $13 C$ ). For each site, the slope of the relationship between the number of spikes in the control response and the number of spikes blocked by AP5 was slightly different. However, the fits were all good ( $r^{2}$ values ranged from 0.880 to 0.987 ). In order to show the data in a single plot, data were normalized by expressing the number of spikes in the control response as a fraction of the maximum control response at each site. In addition, the number of spikes blocked by AP5 was expressed as a fraction of the number predicted by the regression line to occur for the strongest response. At no site was there any tendency for AP5 to block weaker responses less than stronger responscs. These data indicate that even the weakest auditory stimuli activate NMDA receptor currents as effectively as the strongest stimuli. The observation that AP5 blocked spontaneous spikes at all spontaneously active ICx sites (data not shown, but examples in Figs. 2, 9) shows, in addition, that spontaneously active neurons are already depolarized sufficiently to allow NMDA receptors to pass current.

\section{Discussion}

Auditory transmission in the ICX and lateral shell is mediated primarily by excitatory amino acid receptors

Combined application of AP5 and CNQX eliminated a mean of $84 \%$ of auditory-evoked action potentials in the external nucleus and $62 \%$ of auditory-evoked action potentials in the lateral shell of the central nucleus (Fig. $8 A, B$ ). At some of these sites, the drugs completely abolished auditory responses, and in the ICx, complete response blockade was often achieved by application of AP5 alone (e.g., Fig. 5A). Therefore, it is reasonable to conclude that excitatory amino acid receptors play a primary role in mediating auditory responses in the ICX and lateral shell. This is perhaps not surprising, given that fast excitatory transmission via excitatory amino acid receptors is thought to take place throughout the auditory system (cochlear nuclei: Nemeth et al., 1983; Martin, 1985; Hunter et al., 1993; lateral superior olive: Caspary and Faingold, 1989; Finlayson and Caspary, 1989; nucleus laminaris: Zhou and Parks, 1991; medial nucleus of the trapezoid body: Forsythe and Barnes-Davies, 1993). In addition, this finding is consistent with the presence of glutamate binding sites in the chick's IC (Mitsacos et al., 1990) and the 
rat's IC (Greenamyre et al., 1984; Cotman and Iversen, 1987), with the presence of glutamate-immunoreactive neurons in the rat's IC (Otterson and Storm-Mathisen, 1984), and with previous evidence showing that NMDA receptor antagonists reduce auditory responses in the rat's IC (Faingold et al., 1989b).

The contribution of other, nonglutamatergic transmitter systems to auditory responses in these subdivisions of the owl's IC cannot be excluded with this technique, for two reasons. First, it is possible that the residual responses that often remained during combined AP5 and CNQX application (e.g., Fig. 7B) reflect the participation of nonglutamatergic transmitter systems in the auditory response. However, an equally likely explanation is that we failed to apply enough antagonist at these sites to block all excitatory amino acid receptors completely. This explanation is probable since both AP5 and CNQX are competitive antagonists that could be out-competed by the high concentrations of endogenous agonist thought to be released during normal synaptic transmission (Clements et al., 1992). Second, the extracellular recordings used in this study cannot rule out the existence of subthreshold nonglutamatergic inputs to IC neurons. Therefore, we interpret complete blockade of auditory responses by AP5 and CNQX to indicate only that nonglutamatergic receptor currents, if they are generated during auditory responses, are by themselves insufficient to evoke postsynaptic spikes.

\section{$N M D A$ receptors mediate auditory responses in the $I C x$}

The pharmacology of auditory responses was clearly different between the ICx and the lateral shell (Figs. $6 A-C$, 8). In the ICx, auditory responses were always substantially reduced, and sometimes completely eliminated, by application of AP5 at doses selective for NMDA receptors (Figs. 5, 6A, 9). Multiunit responses were reduced by an average of $55 \%$ by AP5 applied at the standard current levels, and single-unit responses were reduced by an average of $64 \%$. These findings indicate that NMDA receptors are activated by auditory inputs to ICx neurons, and that NMDA receptor currents are a major source contributing to the generation of auditory-evoked spikes in that subdivision.

In addition to the major contribution of NMDA receptors to ICx auditory responses, non-NMDA receptors also contributed, though perhaps to a lesser extent. This conclusion is supported by results from the $\mathrm{A} / \mathrm{A}+\mathrm{C}$ protocol showing that $\mathrm{CNQX}$ significantly blocked AP5-resistant spikes at all but one ICx site (Fig. 8A). Because the AP5 current levels used at these sites produced maximal blockade of auditory responses (Fig. 3), additional antagonism of NMDA receptors would be unlikely to decrease auditory responses further. Thus, even though the selectivity of the CNQX ejection currents was not measured in this study, the blockade of AP5-resistant spikes produced by CNQX application must have resulted from antagonism by CNQX of non-NMDA receptors. Therefore, we conclude that non-NMDA receptors are activated by auditory inputs to the ICx, and that non-NMDA receptor currents contribute to the generation of auditory-evoked spikes.

One important caveat to the interpretation of iontophoretic results is that the reduction in firing rate observed with drug application could result from drug action on neurons providing direct or indirect input to the neurons being recorded. However, the blockade of ICx auditory responses by AP5 must result from an action of AP5 at neurons within the ICX itself, though perhaps not at the same neurons that are being recorded. This conclusion is supported by the fact that the only nearby input neurons to the ICx are located in the lateral shell, and AP5 is relatively ineffective in blocking lateral shell responses (Fig. 6A). Therefore, we believe that the reduction of $\mathrm{ICx}$ auditory responses by AP5 is due to antagonism of NMDA receptors located on ICx neurons.

\section{NMDA receptors contrihute relatively little to auditory responses in the lateral shell}

In the lateral shell, in contrast to the ICx, AP5 reduced control auditory responses by only a small fraction, even at the highest current level (Figs. 5, 6A). On average, AP5 reduced control responses at multiunit sites by only $15 \%$, and at single-unit sites by only $25 \%$, despite the fact that significantly greater response blockade was attained at these same sites with CNQX (Figs. 5, $6 B, C$ ). These findings can be explained by three alternative hypotheses. First, NMDA receptors may play a minor role, relative to non-NMDA receptors, in auditory transmission in the lateral shell. Second, morphological conditions may exist in the lateral shell that render synapses mediating auditory responses less accessible to iontophoresed drugs than synapses in the ICx. This possibility must be considered when using iontophoresis because the spatial distribution of synapses relative to the iontophorcsis site will influence the magnitude of response blockade observed during drug application. Receptor accessibility is a potential problem in the lateral shell, since combined AP5 and CNQX application reduced responses significantly less in this subdivision than in the ICx (hatched bars in Fig. $8 A, B$ ). The third hypothesis is that NMDA receptors are indeed differentially involved in transmission in the two subdivisions, but merely as a consequence of a difference in the involvement of excitatory amino acid receptors in general. For example, if a nonglutamatergic receptor system strongly contributed to auditory responses in the lateral shell, then NMDA receptor antagonists would have only a small effect on auditory responses; however, the relative contribution of NMDA and non-NMDA receptors may be equal in the two subdivisions.

Two lines of evidence argue against the latter two hypotheses. First, if either were true, and AP5's small response blockade in the latcral shell werc duc to cither receptor inaccessibility, or to a significant component of nonglutamatergic transmission, then non-NMDA antagonists would be expected to produce less response blockade in the lateral shell than in the ICx. However, CNQX application was shown to reduce auditory responses by an equal amount at single-unit sites in the two subdivisions (Fig. $6 B$ ). Second, measurements of the $\mathrm{A} / \mathrm{A}+\mathrm{C}$ metric indicate that the magnitude of response blockade produced by AP5 is smaller in the lateral shell than in the ICx even when the overall efficacy of excitatory amino acid antagonists is taken into account by normalizing AP5 blockade by the blockade produced by simultaneous AP5 and CNQX application (Figs. 7, 8C).

The rationale for the $\mathrm{A} / \mathrm{A}+\mathrm{C}$ analysis was that the magnitude of response blockade produced by simultaneous AP5 and CNQX ejection should reflect both receptor accessibility and the proportion of auditory transmission mediated by excitatory amino acid receptors. Therefore, normalizing the AP5 response blockade by this quantity should give a measure of the contribution of NMDA receptors, relative to other ionotropic excitatory amino acid receptors, in mediating auditory responses. The $\mathrm{A} / \mathrm{A}+\mathrm{C}$ metric averaged 0.68 for sites in the $\mathrm{ICx}$, and 0.24 for sites in the lateral shell. A value of 1 for this metric indicates that antagonism of NMDA receptors completely accounted for the 
response blockade produced by excitatory amino acid antagonists at that site. Conversely, a value of 0 indicates that antagonism of non-NMDA receptors completely accounted for the response blockade observed at that site. The results argue strongly, therefore, in favor of the first hypothesis: that NMDA receptors play a smaller role, relative to non-NMDA receptors, in mediating auditory responses in the lateral shell than in the ICx.

This conclusion implies that non-NMDA receptors mediate the bulk of auditory responses in the lateral shell. Indeed, for all lateral shell sites tested with the $\mathrm{A} / \mathrm{A}+\mathrm{C}$ protocol, CNQX significantly blocked AP5-resistant spikes, indicating that these spikes were mediated by non-NMDA receptors (Figs. $7 B, 8 B$ ). This interpretation is valid even though the specificity of iontophoresed CNQX is unknown, because AP5 ejection currents were sufficient to reduce NMDA receptor-mediated auditory responses maximally (Fig. 3), and therefore antagonism by CNQX of NMDA receptors, even if it occurred, could not have accounted for the increased response blockade. Moreover, in an independent set of measurements at single-unit sites in the lateral shell, application of CNQX alone consistently blocked more auditory-evoked spikes than did application of AP5 (Fig. 6C). Therefore, we conclude that non-NMDA receptors are the primary receptors mediating auditory transmission in the lateral shell, and that NMDA receptor currents play a relatively minor role in the generation of lateral shell auditory responses.

It is important to note that these results assume a largely homogeneous distribution of receptor types on ICX and lateral shell neurons, relative to the iontophoresis site. If NMDA receptors were preferentially located on the distal tips of lateral shell dendrites, for example, then AP5, which is likely to be iontophoresed near the soma, may have little effect on lateral shell auditory responses, even though NMDA receptors may in fact contribute to responses of those neurons. This possibility cannot be excluded by any technique that involves drug application from a point source.

\section{Comparison with pharmacology in the rat's IC}

Our data confirm and extend a report showing that AP5 reduced auditory responses in the IC of the rat (Faingold et al., 1989b). In that study, iontophoresis of AP5 reduced auditory responses of $84 \%$ of single neurons in the central nucleus of the IC, using a $10 \%$ reduction of auditory-evoked spikes as the criterion for significance. Analyzed by this criterion, our data show that $70 \%$ of single units in the central nucleus (lateral shell) were affected by AP5, and thus the two data sets are largely in agreement. Despite the large percentage of sites that were affected by AP5, however, it is clear from our data that the magnitude of response blockade produced by AP5 in the barn owl's central nucleus is relatively small compared to that observed in the neighboring external nucleus (Figs. 5, 6A, 7, 8). It is also clear that nonNMDA receptors play a major role in mediating auditory responses in the owl's central nucleus (e.g., Figs. $6 \mathrm{C}, 7 \mathrm{~B}, 8 \mathrm{~B}$ ); this role for non-NMDA receptors was not tested in the earlier study because the quinoxalinedione family of non-NMDA receptor antagonists, including CNQX (Honore et al., 1988), was not yet available.

Time course of NMDA and non-NMDA receptor contributions to auditory responses

Intracellular recordings from a variety of central neurons have shown that the time course of NMDA and non-NMDA receptor currents are quite different. Non-NMDA receptor currents have fast rise and decay times, whereas NMDA receptor currents generally have slow rise and decay times (MacDermott and Dale, 1987; Forsythe and Westbrook, 1988; Hestrin et al., 1990). Though time constants vary from preparation to preparation, NMDA receptor currents can decay as much as 20 times more slowly than non-NMDA receptor currents (Hestrin et al., 1990). Responses to scnsory stimuli may be expected to reflect the different time courses of their underlying currents, and it should be possible to observe correlates of them in the alteration of response time course during AP5 and CNQX application. Such observations have been reported for sensory responses in the lateral geniculate (Hartveit and Heggelund, 1990; Kwon et al., 1991), ventrobasal thalamus (Salt, 1987; Salt and Eaton, 1991), and somatosensory cortex (Armstrong-James et al., 1993).

In the ICx, AP5 blocked an increasing percentage of auditoryevoked spikes with increasing time after stimulus onset. AP5 had no effect on the number of spikes occurring in the first few milliseconds of phasic-tonic and tonic responses (Fig. 10 A, C), and the magnitude of response blockade increased with time after stimulus onset for these responses and for phasic responses as well (Figs. 10, 11). In contrast, CNQX blocked early spikes in phasic-tonic and tonic responses, and the magnitude of blockade by CNQX remaincd rclatively constant over the time course of the response (Fig. 10B,C). The analysis of average spike arrival time confirmed these effects of AP5 and CNQX, and showed that they were consistent from neuron to neuron (Fig. 12). Together, these data suggest that early spikes in ICX auditory responses are generated primarily by non-NMDA receptor currents, and that later spikes are supported by both NMDA and non-NMDA receptor currents, with the NMDA receptor component increasing over the course of the response.

The effects of AP5 and CNQX blockade on response time course can be explained by a straightforward model for the activation of NMDA and non-NMDA receptors during synaptic transmission in the ICx. Lateral shell neurons are known to respond tonically to acoustic stimulation (Wagner, 1990; D. E. Feldman and E. I. Knudsen, unpublished observations), and therefore they provide tonic excitatory input to ICx cells during auditory stimulation. We suggest that each incoming action potential carried by lateral shell axons activates both NMDA and non-NMDA receptors on ICx cells. Activation of NMDA receptors appears to lead directly to the generation of NMDA receptor currents, since ICx cells appear to be at or above NMDA receptor threshold (Fig. 13, and see below). As a result, each incoming action potential would evoke a rapid, short-lived, nonNMDA-dependent postsynaptic current (EPSC), and a slower and longer-lived NMDA-dependent EPSC. Because of their long time course, NMDA receptor currents would summate effectively during the tonic input train, making the NMDA receptor current an increasingly dominant component of the total current late in the spike train. In contrast, the shorter-lived non-NMDA EPSCs would summate less effectively, so that the contribution of non-NMDA receptor currents would remain relatively constant throughout the response.

\section{Role of NMDA receptors in auditory processing in the ICX}

The role of NMDA receptors in mediating auditory responses in the ICx stands in contrast to the well-described role of NMDA receptors in synaptic transmission in the hippocampus (Collingridge and Bliss, 1987; Madison et al., 1991). In the hippocampus, NMDA receptors are thought not to pass current in re- 
sponse to low levels of synaptic input, but instead are recruited only during periods of intense synaptic activity, which depolarizes the postsynaptic cell beyond a critical threshold. Suprathreshold depolarization allows NMDA receptor channels to be relieved of a chronic, voltage-sensitive, magnesium ion blockade (Nowack et al., 1984; Ascher and Nowack, 1988). Until this blockade is overcome, NMDA receptors contribute little to normal synaptic transmission. Such a minor role for NMDA receptor currents in normal synaptic transmission has been observed in a variety of in vitro preparations, including the hippocampus (Herron et al., 1986), striate cortex (Artola and Singer, 1987), frontal cortex (Sutor and Hablitz, 1989), and optic tectum (Hickmott and Constantine-Paton, 1993), and in vivo in the retinotectal systems of both the frog (Udin et al., 1992) and the rat (Roberts et al., 1991). Wc found, in contrast, that NMDA receptors participate strongly in normal sensory responses in the barn owl's ICX. Similar results have been found in a variety of in vivo preparations, including the striate cortex (Tsumoto et al., 1987; Fox et al., 1989; Miller et al., 1989), somatosensory cortex (Armstrong-James et al., 1993), lateral geniculate nucleus (Heggelund and Hartveit, 1990; Kwon et al., 1991, 1992), and ventrobasal thalamus (Salt, 1987; Salt and Eaton, 1989, 1991; Eaton and Salt, 1990). Together these data indicate that in many intact preparations, NMDA receptors can participate strongly in normal sensory transmission (for review, see Nelson and Sur, 1992; Daw et al., 1993).

We looked for evidence of an NMDA receptor threshold within the dynamic range of units in the ICx by measuring the percentage of auditory-evoked spikes blocked by AP5 in responses to sounds of different levels (Fig. 13). No threshold was evident. Instead, we found that NMDA receptors contributed equally to the weakest and strongest responses. Moreover, since AP5 blocked the spontaneous activity of all spontaneously active ICx units (e.g., Fig. 2), NMDA receptors must also contribute to the generation of spontaneous action potentials. These findings suggest either that the threshold for NMDA receptor activation lies below the resting membrane potential of ICx neurons, or that the threshold is above resting potential, but close enough to it to be surpassed by the synaptic activity necessary to generate a single postsynaptic spike. NMDA receptors are also thought to be suprathreshold over the entire dynamic range of units in the cat's visual cortex (Fox et al., 1990) and lateral geniculate nucleus (Kwon et al., 1992), based on responses to visual stimuli of different contrasts. In these systems, as in the barn owl's ICx, NMDA receptors were found to support an equal percentage of the weakest and strongest responses.

What special role, if any, NMD $\Lambda$ receptors play in sensory processing has been the topic of recent discussion (Nelson and Sur, 1992; Daw et al., 1993). Fox et al. (1990) have proposed that the NMDA receptor's intrinsic voltage dependence may confer upon it the ability to regulate the gain of neuronal inputoutput functions in the visual cortex. The effect of AP5 on levelresponse curves in the ICX suggests that NMDA receptors may play a similar role in this system. With AP5 present (i.e., with many NMDA receptors antagonized), the dynamic range of ICx neurons remains unchanged, but sound levels are encoded over a much narrower range of output firing rates. Thus, the gain of the input-output function of these neurons is greatly reduced when NMDA receptors are blocked (Fig. 13A). This finding suggests that regulation of NMDA receptor activation in vivo may result in gain adjustments of ICx neurons. Such gain adjustments could, for example, serve to amplify or attenuate neuronal responses based on attention (cf. Moran and Desimone, 1985) or other processes.

Another possibility is that NMDA receptors in the ICx are important for the integration of auditory information across frequency channels, which is the final step in the synthesis of the auditory space map that occurs within the ICx (Konishi et al., 1988). One possible role for NMDA receptors in this process is in the alteration of ITD tuning that occurs when information is integrated across frequencies. This alteration involves the selective suppression of responses to phase-ambiguous ITD values (Takahashi and Konishi, 1986), which are ITD values that are displaced from the main ITD tuning peak by multiples of the period of each unit's best frequency. Suppression of these "side peaks" is important in creating spatially restricted auditory receptive fields (Brainard et al., 1992), and is known to take place in the ICx through GABA-mediated synaptic inhibition (Fujita and Konishi, 1991). It has been suggested for other systems that inhibitory inputs, because they reduce postsynaptic membrane potential, dramatically attenuate voltage-sensitive NMDA receptor currents (Daw et al., 1993). It follows that inputs mediated via NMDA receptors would be potently attenuated by inhibition. It is possible, therefore, that the great reliance on NMDA receptors in the ICx enables the powerful inhibition of responses to phase-ambiguous ITDs. Further evidence for this possible role of NMDA receptors comes from the observation that side-peak responses in the ICx are suppressed dynamically over the time course of the response (Wagner, 1990), in parallel with the increasing NMDA receptormediated component of the auditory response shown here.

\section{$N M D A$ receptors and experience-dependent plasticity in the $I C x$}

In addition to whatever function they have in auditory processing, NMDA receptors may also play a role in the experiencedependent plasticity known to occur in the barn owl's ICx. The auditory and visual space maps that exist in the optic tectum are mutually aligned, and that alignment is maintained through a dynamic process of visually guided adjustment of auditory receptive fields in the ICx (Brainard and Knudsen, 1993). During the adjustment process, the tuning of $\mathrm{ICx}$ neurons to binaural localization cues (ITD and ILD) systematically changes so that responses to visually appropriate cue values are enhanced, and responses to inappropriate cue values are lost. A similar experience-dependent alignment of sensory maps occurs in the optic tectum of Xenopus, and this alignment has been shown to be dependent on the activation of NMDA receptors (Scherer and Udin, 1989). NMDA receptors have also been implicated in other forms of activity-dependent plasticity, including the segregation of eye-specific stripes in the tecta of three-eyed frogs (Cline et al., 1987), receptive field sharpening in the regenerating retinotectal projection of goldfish (Schmidt, 1990), development of ocular dominance columns in the visual cortex of kittens (Bear et al., 1990), and the formation of on/off sublaminae in the lateral geniculate nucleus of kittens (Hahm et al., 1991).

The fact that NMDA receptors are present and functional in the ICx suggests that NMDA receptors may be a substrate for the synaptic modifications that occur in this structure, particularly in light of the fact that these receptors contribute to auditory responses most strongly in exactly the subdivision of the IC in which experience-dependent synaptic modification is known to occur (Brainard and Knudsen, 1993). What role they may play in this modification is not known. However, their 
routine contribution to auditory responses makes it unlikely that they provide the sole trigger necessary for induction of synaptic modification, as has been suggested in the hippocampus (Collingridge and Bliss, 1987; but see Madison et al., 1991), frog tectum (Cline, 1991), and visual cortex (Bear et al., 1990). Indeed, routine activation of NMDA receptor currents eliminates the very feature of NMDA receptors that first made them attractive theoretical candidates for gating synaptic modifications: their ability to detect correlations between high levels of preand postsynaptic activity (Stent, 1973; Brown et al., 1990). Instead, if NMDA receptors are involved in synaptic modification in the ICx, there must be an additional integrative step downstream of NMDA receptor-mediated calcium entry that regulates synaptic efficacy. Otherwise, synaptic modification would be "triggered" by every input to the postsynaptic cell. This same conclusion has been drawn for the putative involvement of NMDA receptors in experience-dependent plasticity in kitten visual cortex (Fox et al., 1990) and rat somatosensory cortex (Armstrong-James et al., 1993).

\section{Conclusions}

Until recently, NMDA receptors were viewed as silent partners in normal synaptic transmission, being important not in the generation of action potentials in response to routine synaptic input, but only as a trigger for synaptic modification in the case of highly intense or convergent stimulation (Collingridge and Bliss, 1987). However, the data presented here, together with mounting data from other preparations, demonstrate that NMDA receptors play an important role in normal sensory information processing. This role, which remains to be completely elucidated, may be independent of any role these receptors may play in activity-dependent synaptic modification.

\section{References}

Adams JC, Wenthold RJ (1979) Distribution of putative amino acid transmitters, choline acetyltransferase, and glutamate decarboxylase in the inferior colliculus. Neuroscience 4:1947-1951.

Armstrong-James M, Millar J (1979) Carbon fibre microelectrodes. J Neurosci Methods 1:279-287.

Armstrong-James M, Welker E, Callahan CA (1993) The contribution of NMDA and non-NMDA receptors to fast and slow transmission of sensory information in the rat S1 barrel cortex. J Neurosci 13: $2149-2160$.

Artola A, Singer W (1987) Long-term potentiation on NMDA receptors in rat visual cortex. Nature 330:649-652.

Ascher P, Nowack L (1988) The role of divalent cations in the $N$-methyl-D-aspartate responses of mouse central neurones in culture. $J$ Physiol (Lond) 339:247-266.

Bcar MF, Klcinschmidt A, Gu Q, Singer W (1990) Disruption of experience-dependent synaptic modifications in striate cortex by infusion of an NMDA receptor antagonist. J Neurosci 10:909-925.

Brainard MS, Knudsen EI (1993) Experience-dependent plasticity in the inferior colliculus: a site for visual calibration of the neural representation of auditory space in the barn owl. J Neurosci 13:45894608.

Brainard MS, Knudsen EI, Esterly SD (1992) Neural derivation of sound source localization: resolution of spatial ambiguities in binaural cues. J Acoust Soc Am 91:1015-1027.

Brown TH, Kairiss EW, Keenan CL (1990) Hebbian synapses: biophysical mechanisms and algorithms. Annu Rev Neurosci 13:475511.

Caspary DM, Faingold CL (1989) Non- $N$-methyl-D-aspartate receptors may mediatc ipsilatcral cxcitation at latcral supcrior olivary synapses. Brain Res 503:83-90.

Clements JD, Lester RA, Tong G, Jahr CE, Westbrook GL (1992) The timecourse of glutamate in the synaptic cleft. Science 258:1498-1501.

Cline HT (1991) Activity-dependent plasticity in the visual systems of frogs and fish. Trends Neurosci 14:104-111.
Cline HT, Debski EA, Constantine-Paton M (1987) N-methyl-D-aspartate receptor antagonist desegregates eye-specific stripes. Proc Natl Acad Sci USA 84:4342-4345.

Collingridge GL, Bliss TVP (1987) NMDA receptors-their role in long-term potentiation. Trends Neurosci 10:288-293.

Cotman CW, Iversen LL (1987) Excitatory amino acids in the brainfocus on NMDA receptors. Trends Neurosci 10:263-265.

Daw NW, Stein PSG, Fox K (1993) The role of NMDA receptors in information processing. Annu Rev Neurosci 16:207-222.

Eaton SA, Salt TE (1990) Thalamic NMDA receptors and nociceptive sensory synaptic transmission. Neurosci Lett 110:297-302.

Faingold CL, Gehlbach G, Caspary DM (1989a) On the role of GABA as an inhibitory neurotransmitter in inferior colliculus neurons: iontophoretic studies. Brain Res 500:302-312.

Faingold CL, Hoffman WE, Caspary DM (1989b) Effects of excitant amino acids on acoustic responses of inferior colliculus neurons. Hearing Res 40:127-136.

Faingold CL, Boersma-Anderson CA, Caspary DM (1991) Involvement of GABA in acoustically-evoked inhibition in inferior colliculus neurons. Hearing Res 52:201-216.

Finlayson PG, Caspary DM (1989) Synaptic potentials of chinchilla lateral superior olivary neurons. Hearing Res 38:221-228.

Forsythe ID, Barnes-Davies M (1993) The binaural auditory pathway: excitatory amino acid receptors mediate dual timecourse excitatory postsynaptic currents in the rat medial nucleus of the trapezoid body. Proc R Soc Lond [Biol] 251:151-157.

Forsythe ID, Westbrook GL (1988) Slow excitatory postsynaptic currents mediated by $N$-methyl-D-aspartate receptors on cultured mouse central neurones. J Physiol (Lond) 396:515-533.

Fox K, Sato H, Daw N (1989) The location and function of NMDA receptors in cat and kitten visual cortex. J Neurosci 9:2443-2454.

Fox K, Sato H, Daw N (1990) The effect of varying stimulus intensity on NMDA-receptor activity in cat visual cortex. J Neurophysiol 64: 1413-1428.

Fujita I, Konishi M (1991) The role of GABAergic inhibition in processing of interaural time difference in the owl's auditory system. $J$ Neurosci 1:722-739.

Golden GT, Ferraro TN, Rariello RG, Theodore AH (1989) Amino acid profiles in Long-Evans rat superior colliculus, visual cortex, and inferior colliculus. Neurochem Res 14:465-472.

Greenamyre JT, Young AB, Peney JB (1984) Quantitative autoradiographic distribution of $\mathrm{L}-\left[{ }^{3} \mathrm{H}\right]$ glutamate-binding sites in rat central nervous system. J Neurosci 4:133-134.

Hahm J-O, Langton RB, Sur M (1991) Disruption of retinogeniculate afferent segregation by antagonists to NMDA receptors. Nature 351 : 568-570.

Hartveit E, Heggelund $P$ (1990) Neurotransmitter receptors mediating excitatory input to cells in the cat lateral geniculate nucleus. II. Nonlagged cells. J Neurophysiol 63:1361-1372.

Heggelund P, Hartveit E (1990) Neurotransmitter receptors mediating excitatory input to cells in the cat lateral geniculate nucleus. I. Lagged cells. J Neurophysiol 63:1347-1360.

Heilegenberg W (1991) The jamming avoidance response of the electric fish, Eigenmannia: computational rules and their neural implementation. Semin Neurosci 3:3-18.

Herron CE, Lester RAJ, Coan EJ, Collingridge GL (1986) Frequencydependent involvement of NMDA receptors in the hippocampus: a novel synaptic mechanism. Nature 322:265-268.

Hestrin S, Nicoll RA, Perkel DJ, Sah P (1990) Analysis of excitatory synaptic action in pyramidal cells using whole-cell recording from rat hippocampal slices. J Physiol (Lond) 422:203-225.

Ilickmott PW, Constantine-Paton M (1993) The contributions of NMDA, non-NMDA, and GABA receptors to postsynaptic responses in neurons of the optic tectum. J Neurosci 13:4339-4353.

Honore T, Davies SN, Drejer J, Fletcher EJ, Jacobsen P, Lodge D, Nielsen FE (1988) Quinoxalinediones: potent competitive non- $N$ methyl-D-aspartate glutamate receptor antagonists. Science 241:701703.

Hunter C, Petralia RS, Vu T, Wenthold RJ (1993) Expression of AMPA-selective glutamate receptor subunits in morphologically defined neurons of the mammalian cochlear nucleus. J Neurosci 13: 1932-1946.

Irvine DRF (1986) The auditory brainstem. New York: Springer.

Irvine DRF, Gago G (1990) Binaural interaction in high-frequency neurons in inferior colliculus of the cat: effects of variations in sound 
pressure level on sensitivity to interaural intensity differences. J Neurophysiol 63:570-591.

Knudsen EI (1983) Subdivisions of the inferior colliculus in the barn owl Tyto alba. J Comp Neurol 218:174-186.

Knudsen EI, Konishi M (1978) A neural map of auditory space in the owl. Science 200:795-797.

Knudsen EI, Knudsen PF, Masino T (1993) Parallel pathways mediating both sound localization and gaze control in the forebrain and midbrain of the barn owl. J Neurosci 13:2837-2852.

Konishi M, Takahashi TT, Wagner H, Sullivan WE, Carr CE (1988) Neurophysiological and anatomical substrates of sound localization in the barn owl. In: Auditory function (Edelman GE, Gall WE, Cowan WM, eds). New York: Wiley.

Kwon YH, Esguerra M, Sur M (1991) NMDA and non-NMDA receptors mediate visual responses of neurons in the cat's lateral geniculate nucleus. J Neurophysiol 66:414-428.

Kwon YH, Nelson SB, Toth LJ, Sur M (1992) Effect of stimulus contrast and size on NMDA receptor activity in cat lateral geniculate nucleus. J Neurophysiol 68:182-196.

MacDermott AB, Dale N (1987) Receptors, ion channels and synaptic potentials underlying the integrative actions of excitatory amino acids. Trends Neurosci 10:280-284.

Madison DV, Malenka RC, Nicoll RA (1991) Mechanisms underlying long-term potentiation of synaptic transmission. Annu Rev Neurosci 14:379-398.

Martin MR (1985) Excitatory amino acid pharmacology of the auditory nerve and nucleus magnocellularis of the chicken. Hearing Res 17:153-160.

Mayer ML, Westbrook GL (1987) The physiology of excitatory amino acids in the vertebrate central nervous system. Prog Neurobiol 28: 197-276.

Miller KD, Chapman B, Stryker MP (1989) Visual responses in adult cat visual cortex depend on $N$-methyl-D-aspartate receptors. Proc Natl Acad Sci USA 86:5153-5187.

Mitsacos A, Dermon CR, Stasi K, Kouvelas ED (1990) Localization of L-glutamate binding sites in chick brain by quantitative autoradiography. Brain Res 513:348-352.

Mogdans J, Knudsen EI (1993) Early monaural occlusion alters the neural map of interaural level differences in the inferior colliculus of the barn owl. Brain Res 619:29-38.

Moiseff A, Konishi M (1981) The owl's interaural pathway is not involved in sound localization. J Comp Neurol 144:299-304.

Moran J, Desimone R (1985) Selective attention gates visual processing in the extrastriate cortex. Science 229:782-784.

Nelson SB, Sur M (1992) NMDA receptors in sensory information processing. Curr Opin Neurobiol 2:484-488.

Nemeth EF, Jackson H, Parks TN (1983) Pharmacologic evidence for synaptic transmission mediated by non- $N$-methyl-D-aspartate receptors in the avian cochlear nucleus. Neurosci Lett 40:39-44.

Neter J (1990) Applied linear statistical models, 3d ed. Homewood, IL: Irwin.

Nicoll RA, Malenka RC, Kauer JA (1990) Functional comparison of neurotransmitter receptor subtypes in mammalian central nervous system. Physiol Rev 70:513-565.

Nowack L, Bregestovski P, Ascher P, Herbert A, Prochianz A (1984) Magnesium gates glutamate activated channels in mouse central neurones. Nature 307:462-465.

Oliver DL, Huerta MF (1992): Inferior and superior colliculi. In: The mammalian auditory pathway: neuroanatomy (DB Webster, AN Popper, RR Fay, eds), pp 168-221. New York: Springer.

Ottersen OP, Storm-Mathisen J (1984) Glutamate- and GABA-containing neurons in the mouse and rat brain, as demonstrated with a new immunocytochemical technique. J Comp Neurol 229:374-392.

Park TJ, Pollak GD (1993) GABA shapes sensitivity to interaural intensity disparities in the mustache bat's inferior colliculus: implications for encoding sound location. J Neurosci 13:2050-2067.

Roberts WA, Eaton SA, Salt TE (1991) Excitatory amino acid receptors mediate synaptic responses to visual stimuli in superior colliculus neurones of the rat. Neurosci Lett 129:11-14.

Salt TE (1987) Excitatory amino acid receptors and synaptic transmission in the rat ventrobasal thalamus. J Physiol (Lond) 391:499510.

Salt TE, Eaton SA (1989) Function of non-NMDA receptors and NMDA receptors in synaptic responses to natural somatosensory stimulation in the ventrobasal thalamus. Exp Brain Res 77:646-652.

Salt TE, Eaton SA (1991) Sensory excitatory postsynaptic potentials mediated by NMDA and non-NMDA receptors in the thalamus. Eur J Neurosci 3:296-300.

Scherer WJ, Udin SB (1989) $N$-methyl-D-aspartate antagonists prevent interaction of binocular maps in Xenopus tectum. J Neurosci 9:3837-3843.

Schmidt JT (1990) Long-term potentiation and activity-dependent retinotopic sharpening in the regenerating retinotectal projection of goldfish: common sensitive period and sensitivity to NMDA blockers. J Neurosci 10:233-246.

Shatz CJ (1990) Impulse activity and the patterning of connections during CNS development. Neuron 5:745-756.

Smith PH (1992) Anatomy and physiology of multipolar cells in the rat inferior collicular cortex using the in vitro brain slice technique. J Neurosci 12:3700-3715.

Stent GS (1973) A physiological mechanism for Hebb's postulate of learning. Proc Natl Acad Sci USA 70:997-1001.

Sutor B, Hablitz JJ (1989) EPSPs in rat neocortical neurones in vitro. II. Involvement of $N$-methyl-D-aspartate receptors in the generation of EPSPs. J Neurophysiol 61:621-634.

Takahashi TT, Konishi M (1986) Selectivity for interaural time difference in the owl's midbrain. J Neurosci 6:3413-3422.

Tsumoto T, Haghihara H, Sato H, Hata Y (1987) NMDA receptors in the visual cortex of young kittens are more effective than those of adult cats. Nature 327:513-514.

Udin SB, Scherer WJ, Constantine-Paton M (1992) Physiological effects of chronic and acute application of $N$-methyl-D-aspartate and 5-amino-phosphonovaleric acid to the optic tectum of Rana pipiens frogs. Neuroscience 49:739-747.

Wagner H (1990) Receptive fields of neurons in the owl's auditory brainstem change dynamically. Eur J Neurosci 2:949-959.

Wagner H, Takahashi T, Konishi M (1987) Representation of interaural time difference in the central nucleus of the barn owl's inferior colliculus. J Neurosci 7:3105-3116.

Wenstrup JJ, Ross LS, Pollak GD (1986) Binaural response organization within a frequency-band representation of the inferior colliculus: implications for sound localization. J Neurosci 6:962-973.

Zhou N, Parks TN (1991) Pharmacology of excitatory amino acid neurotransmission in nucleus laminaris of the chick. Hearing Res 52: 195-200. 